\title{
Hypervalent organoiodine compounds: from reagents to valuable building blocks in synthesis
}

\author{
Gwendal Grelier, Benjamin Darses and Philippe Dauban ${ }^{*}$
}

\author{
Review \\ Address: \\ Institut de Chimie des Substances Naturelles, CNRS UPR 2301, \\ Université Paris-Sud, Université Paris-Saclay, 1, av. de la Terrasse, \\ 91198 Gif-sur-Yvette, France \\ Email: \\ Philippe Dauban* - philippe.dauban@cnrs.fr \\ * Corresponding author \\ Keywords: \\ atom-economy; couplings; hypervalent iodine; oxidation; tandem \\ reactions
}

\author{
Beilstein J. Org. Chem. 2018, 14, 1508-1528. \\ doi:10.3762/bjoc. 14.128 \\ Received: 20 February 2018 \\ Accepted: 25 May 2018 \\ Published: 21 June 2018 \\ This article is part of the Thematic Series "Hypervalent iodine chemistry in \\ organic synthesis". \\ Guest Editor: T. Wirth \\ C 2018 Grelier et al.; licensee Beilstein-Institut. \\ License and terms: see end of document.
}

\begin{abstract}
Most of the polyvalent organoiodine compounds derive from iodoarenes, which are released in stoichiometric amounts in any reaction mediated by $\lambda^{3}$ - or $\lambda^{5}$-iodanes. In parallel to the development of solid-supported reagents or reactions catalytic in iodine, a third strategy has emerged to address this issue in terms of sustainability. The atom-economy of transformations involving stoichiometric amounts of $\lambda^{3}$ - or $\lambda^{5}$-iodanes, thus, has been improved by designing tandem reactions that allows for incorporating the aryl motif into the products through a subsequent one-pot nucleophilic addition or catalytic coupling reaction. This review summarizes the main achievements reported in this area.
\end{abstract}

\section{Introduction}

Synthetic applications of the hypervalent iodine chemistry have grown exponentially in the last four decades as highlighted by several books and comprehensive reviews dedicated to this topic [1-13]. A still growing number of $\lambda^{3}$ - and $\lambda^{5}$-iodanes are now available as non-toxic and environmentally benign reagents that allow for performing a wide range of transformations under mild conditions. The oxidation of functional groups, halogenations, $\mathrm{C}-\mathrm{C}, \mathrm{C}-\mathrm{O}$, or $\mathrm{C}-\mathrm{N}$ couplings, dearomatization of phenols, rearrangements, to name but a few, have been reported using these compounds thereby reflecting their versatility.
A survey of the general structure of polyvalent organoiodine compounds reveals that they are prepared mostly from iodoarene starting materials. Accordingly, any transformation relying on stoichiometric amounts of these reagents will inevitably produce the same quantity of iodoarene derivatives, which can be considered as a waste in the context of sustainable chemistry. Various strategies, thus, have been described to address this issue. A first solution has arisen from the development of polystyrene-supported reagents, which allows their recycling following simple filtration and re-oxidation (reaction 1 in Scheme 1a) [14,15]. More recently, the design of 
a) Acknowledged strategies

(1) Solid-supported reagents

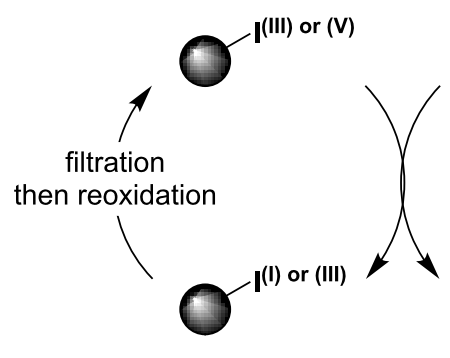

substrate

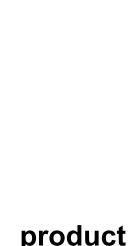

b) Focus of this review

(1) Tandem additions

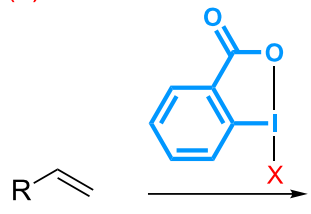

(2) Hypervalent iodine catalysis
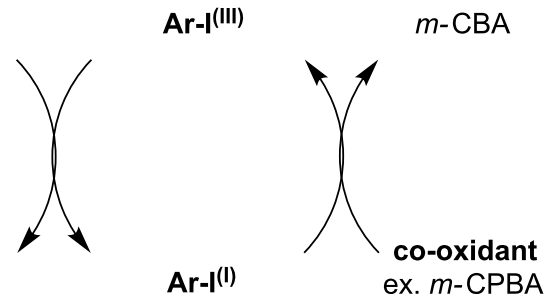

(3) Tandem oxidation-catalytic coupling

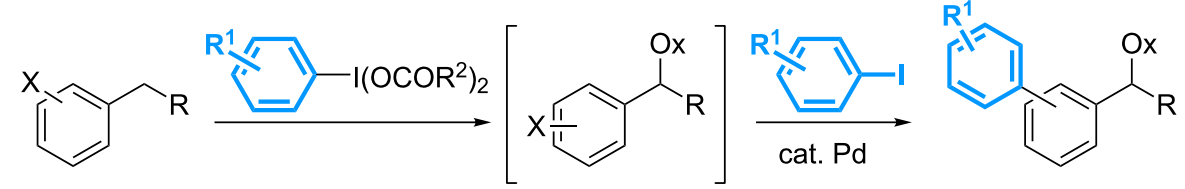

Scheme 1: Strategies to address the issue of sustainability with polyvalent organoiodine reagents.

processes catalytic in iodine compounds has been extensively investigated and significant achievements have been reported making iodine compounds now useful organocatalysts in asymmetric synthesis (reaction 2 in Scheme 1a) [15-24].

In parallel to these investigations, a third strategy has been envisaged with the development of tandem reactions involving a step that enables the introduction of the iodoarene side-compound into the products. Various sequences combining oxidation reactions, nucleophilic additions, or aromatic couplings, thus, have been reported (Scheme 1b). In addition to address the issue of sustainability, this complementary solution has provided opportunities to explore a new chemical space. This review aims to highlight the main achievements reported in this context since the first study described in 1995 on the palladium-catalyzed cross couplings of symmetrical diphenyl- $\lambda^{3}$-iodanes with sodium tetraphenylborate [25].

\section{Review}

\section{Tandem additions}

$\lambda^{5}$-Iodanes such as the Dess-Martin periodinane or IBX [26], and $\lambda^{3}$-iodanes such as benziodoxolones [27], are versatile reagents in organic synthesis. These are often used, respectively, for the oxidation of alcohols or carbonyl compounds, and in atom-transfer reactions. These transformations always lead to the release of 2-iodobenzoic acid in the reaction mixture. Thus, with the aim to value this side product, a variety of tandem reactions including an oxidation and an addition step have been designed to incorporate the nucleophilic acid into the final product.

\section{$\lambda^{5}$-lodane reagents}

One of the first studies documenting the use of the iodoarene moiety as a building block in synthesis has been reported in 2004. The $\lambda^{5}$-iodane reagent IBX has been shown to promote the $\alpha$-functionalization of ketones following the introduction of the 2-iodobenzoic acid motif (Scheme 2a) [28].

Mono- and disubstituted products $\mathbf{1}$ and $\mathbf{2}$ are obtained respectively from aliphatic ketones and methyl aryl ketones. The reaction conditions have then been extended to the functionalization of alkenes to afford 1,2-halo-oxygenated compounds 3 (Scheme 2b) [29]. This transformation has recently been used for the stereoselective trans iodo-benzoylation of glycals using a combination of IBX and molecular iodine, that is considered as a source of $\mathrm{I}^{+}$formed from the in situ generated hypoiodite species [30].

The controlled oxidation of various $N$-(alkyl)- and $\mathrm{N}$-(aryl)pyrroles with Dess-Martin periodinane also leads to 
a) $\alpha$-Functionalization of ketones<smiles>[R]CC([R])=O</smiles><smiles>O=C1OI(=O)(O)c2ccccc21</smiles>

$\mathrm{KI}, \mathrm{MeCN}$<smiles>[R]c1ccccc1C(C)=O</smiles><smiles>[R]c1cccc(C(=O)C(OC(=O)c2ccccc2I)OC(=O)c2ccccc2I)c1</smiles>

b) Halo-oxygenation of alkenes<smiles>[R3]C=C([R])[R]</smiles>

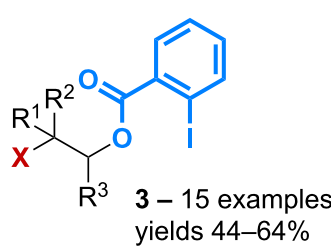

Scheme 2: Functionalization of ketones and alkenes with IBX. introduction of the iodobenzoic acid motif onto the pyrrole ring. 5-Aroyloxy- $\gamma$-lactams 4 can be isolated with yields in the $56-96 \%$ range, however, the reaction requires 2.5 equivalents of the $\lambda^{5}$-iodane reagent, a result that supports its limited efficiency in terms of atom economy (Scheme 3) [31].

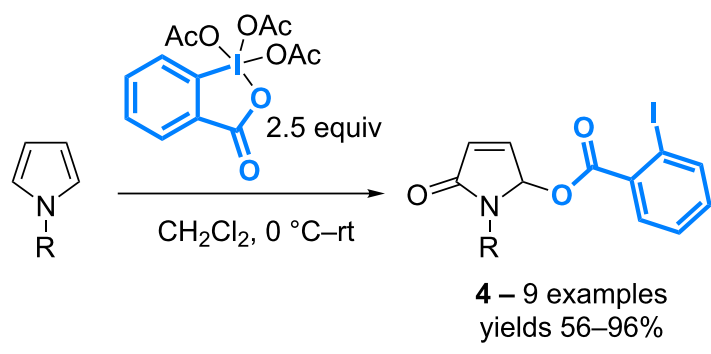

Scheme 3: Functionalization of pyrroles with DMP.

\section{$\lambda^{3}$-lodane reagents: $\mathrm{CF}_{3}$-benziodoxolone (Togni's reagent)}

The ability to introduce the 2-iodobenzoic acid motif released from benziodoxolones has first been noticed by Ochiai in an isolated example of radical benzoyloxylation of THF [32], and by Gouverneur in the study of trifluoromethylation of allylsilanes [33]. The use of this acid as an oxygen nucleophile, then, has been more fully investigated by the groups of Szabó and Sodeoka who have simultaneously described the copper-catalyzed benzoyloxy-trifluoromethylation of alkenes and alkynes using Togni's reagent 5.

The group of Szabó has first reported the use of copper(I) iodide as a catalyst for the regioselective difunctionalization of aromatic alkynes and alkenes with an optimal atom-economy (Scheme 4a) [34,35]. The transformation proceeds efficiently, particularly in the presence of an electron-donating substituent a) Copper-catalyzed benzoyloxy-trifluoromethylation of alkenes and alkynes with Togni's reagent 5

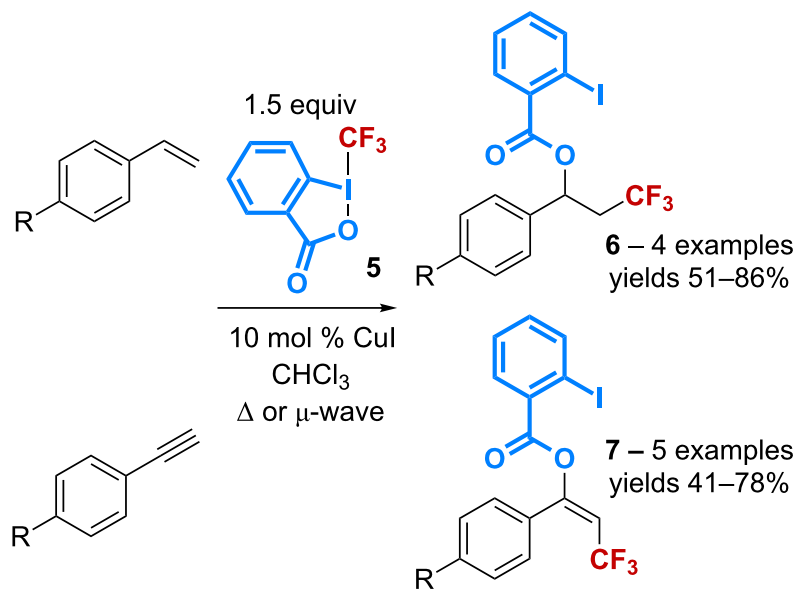

b) Mechanism of the copper-catalyzed benzoyloxytrifluoromethylation

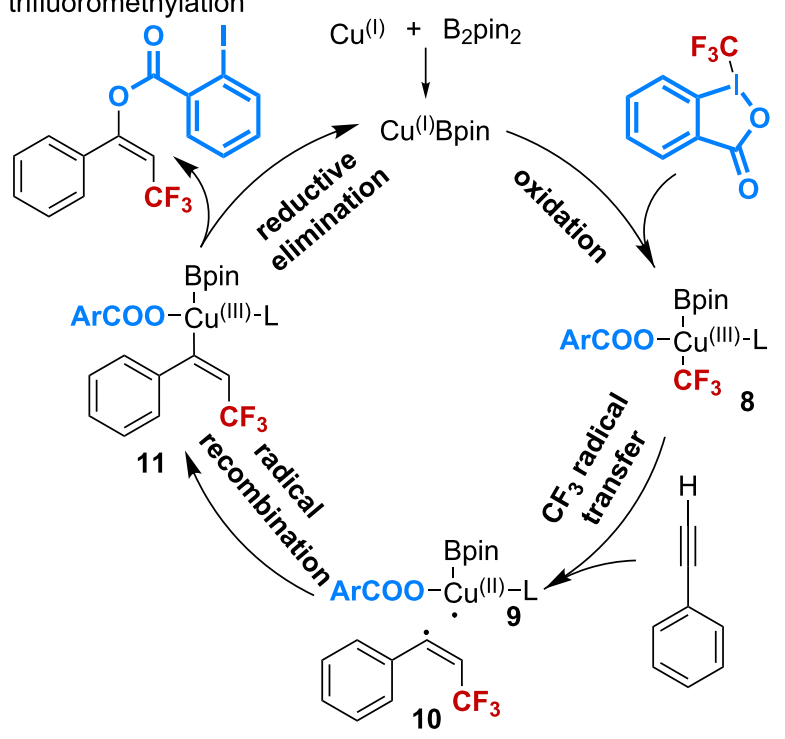


on the aromatic ring. The same reaction has been later found to be mediated by copper(I) cyanide starting from $p$-methoxystyrene [36]. However, under these conditions, other styrene derivatives bearing a phenyl, a tert-butyl, or an electron-withdrawing substituent have been shown to afford products resulting from a cyanotrifluoromethylation reaction.

The mechanistic study of the oxy-trifluoromethylation of phenylacetylene has then led to demonstrate that the reaction is accelerated in the presence of additives such as $\mathrm{B}_{2} \mathrm{pin}_{2}$ [35]. A mechanism involving an initial step of transmetallation of $\mathrm{B}_{2} \mathrm{pin}_{2}$ with the $\mathrm{Cu}(\mathrm{I})$ catalyst was proposed (Scheme $\left.4 \mathrm{~b}\right)$. The intermediate $\mathrm{Cu}-\mathrm{Bpin}$, then, could undergo an oxidative addition into the $\mathrm{CF}_{3}-\mathrm{I}$ bond to give $\mathbf{8}$ that, after a $\mathrm{CF}_{3}$ radical transfer, would afford the radicals $\mathbf{9}$ and $\mathbf{1 0}$. Radical recombination followed by reductive elimination would finally lead to the $E$-product and regenerate the $\mathrm{Cu}$-Bpin complex.

The group of Sodeoka, in parallel, has described the same 1,2difunctionalization reaction of alkenes and alkynes with $\mathbf{5}$ in the presence of $\left[\mathrm{Cu}(\mathrm{MeCN})_{4}\right] \mathrm{PF}_{6}$ as the catalyst (Scheme 5a) [37]. It should be pointed out that this copper(I) complex was previously described by Szabó as a poor catalyst in his process. The reaction applies to phenylacetylenes and various types of aromatic alkenes, however, its scope has been extended to dienes and disubstituted styrenes by using the less Lewis acidic $\mathrm{CuI}$ complex (Scheme 5b) [38]. Interestingly, cis and trans $\beta$-methyl-styrenes lead to product $\mathbf{1 4}$ with the same syn:anti ratio while 1,4-addition products containing an $(E)$-olefin are selectively obtained from dienes. The authors have also shown that the reaction performed in the presence of a stoichiometric amount of $p$-TsOH gives $\beta$-trifluoromethylstyrene derivatives instead of the expected oxy-trifluoromethyl compound.

The benzoyloxy-trifluoromethylation of dienes has also been reported with $\mathrm{CuCN}$ as the catalyst. The reaction, again, is selective with respect to the olefin geometry $-(E)$-alkenes are exclusively obtained - and the regioselectivity - products resulting from a sterically-controlled 1,4-anti-addition are selectively isolated (Scheme 6) [39]. The proposed radical mechanism, which takes into account the beneficial effect of the bulky monophosphine $\mathrm{P}(t-\mathrm{Bu})_{3}$ on the reaction rate, is consistent with that reported by Szabó (Scheme 4b).

The scope of the copper-catalyzed benzoyloxy-trifluoromethylation has been extended to several other substrates. Starting from $N$-(aryl)- and $N$-(benzyl)allylamines $\mathbf{1 6}$, the reaction affords $\beta$-benzoyloxy- $\beta$ '-trifluoromethylamines 17 through the formation of an aziridine intermediate (Scheme 7) [40]. The latter was further utilized to give access to a variety of $\beta$-trifluo-

\section{a) Copper-catalyzed benzoyloxy-trifluoromethylation of} aromatic alkenes and phenylacetylenes

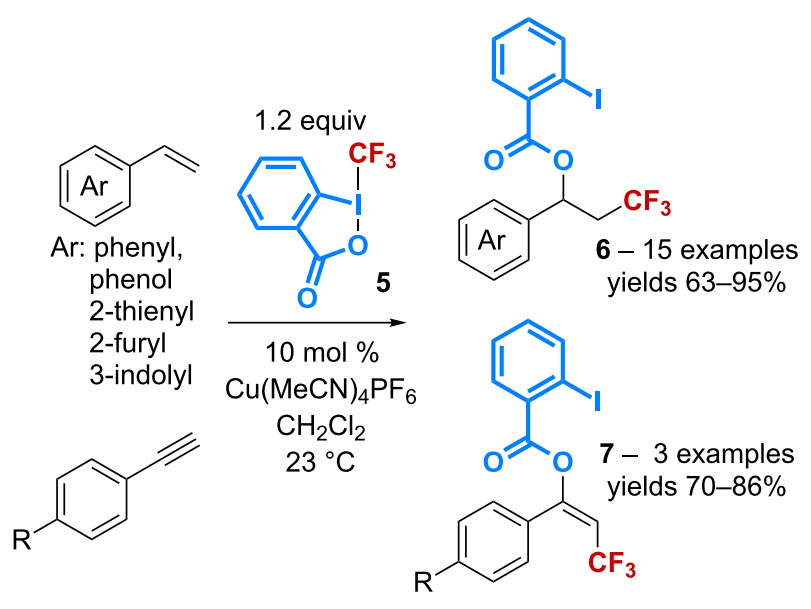

b) Copper-catalyzed benzoyloxy-trifluoromethylation of disubstituted styrenes and dienes<smiles>[R]C(=C)c1ccccc1</smiles><smiles>O=C1OI(C(F)(F)F)c2ccccc21</smiles>

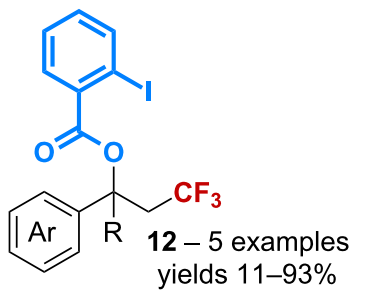

$20 \mathrm{~mol} \% \mathrm{Cul}$ $\mathrm{CH}_{2} \mathrm{Cl}_{2}$ $40{ }^{\circ} \mathrm{C}$<smiles>CC=Cc1ccc(OC)cc1</smiles>

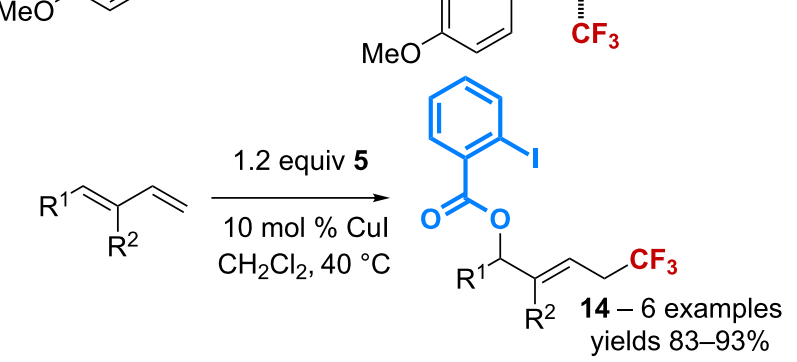




$$
\text { R': large substituent }
$$<smiles>[R]/C(=C(\[R])C([R9])(C)C)C([R9])OC(=O)c1ccccc1I</smiles>

15 - 11 examples yields $58-74 \%$

Scheme 6: Catalytic 1,4-benzoyloxy-trifluoromethylation of dienes.

romethylamines after reaction with several $O-, N-, S$-, and $C$-nucleophiles.

$$
16
$$

Scheme 7: Catalytic benzoyloxy-trifluoromethylation of allylamines.

Application of the same reaction conditions to enynes $\mathbf{1 8}$ has led to the discovery of an elegant cascade that gives access to a wide range of trifluoromethylated five-membered carbo- and heterocycles 19 (Scheme 8) [41]. Six-membered heterocycles

can also be obtained in good yields. The reaction is believed to involve either a tertiary radical intermediate or a carbocationic species, both being able to undergo a 5-exo-dig type cyclization to afford compounds 19.

The copper-catalyzed benzoyloxy-trifluoromethylation has also been applied to the conversion of allenes $\mathbf{2 0}$. A regioselective 1,2 -addition on the internal $\pi$-bond was observed to afford the products $\mathbf{2 1}$, because of the presence of a heteroatom substituent that can stabilize the radical or cationic intermediate by coordination with the copper complex (Scheme 9) [42]. However, the efficiency of the reaction is limited by the need to use 2 equivalents of allenes $\mathbf{2 0}$ to obtain good yields.

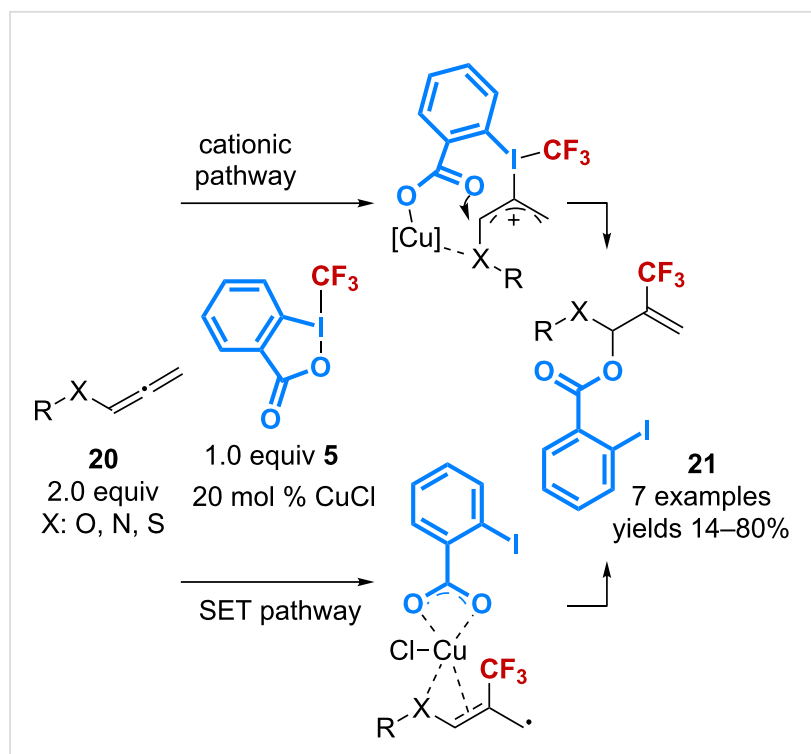

Scheme 9: Catalytic benzoyloxy-trifluoromethylation of allenes.

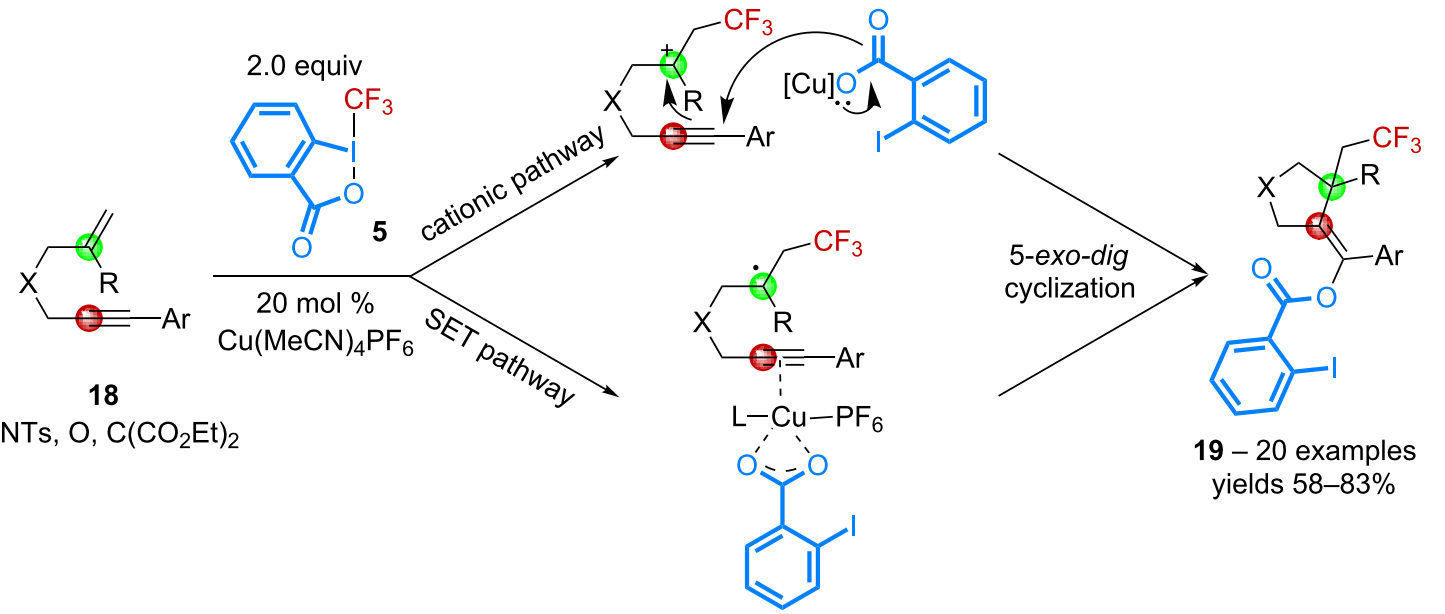

Scheme 8: Catalytic benzoyloxy-trifluoromethylation of enynes. 


\section{$\lambda^{3}$-lodane reagents: alkynylbenziodoxolone}

Ethynylbenziodoxolone (EBX) is a powerful reagent to perform the electrophilic alkynylation of various functional groups such as carbonyl derivatives, thiols, arenes and heteroarenes [43,44]. A first solution to value the 2-iodobenzoic moiety released from EBX has arisen from the reaction of derivatives 22 with $\mathrm{N}$-(aryl)imines $\mathbf{2 3}$ in the presence of $10 \mathrm{~mol} \%$ of $\mathrm{Pd}(\mathrm{OAc})_{2}$, which gives access to tri- or tetrasubstituted furans $\mathbf{2 4}$ and $\mathrm{N}$-(aryl)formamides 25 (Scheme 10a) [45]. The scope of the overall transformation is wide both in terms of imines and EBX reagents.

a) EBX reagents for the formation of substituted furans

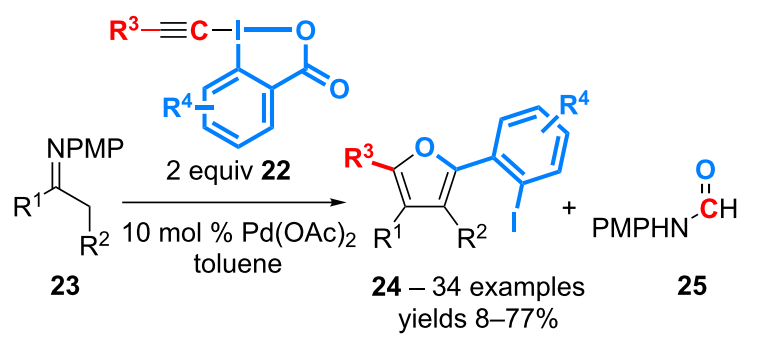

b) Mechanism for the reaction

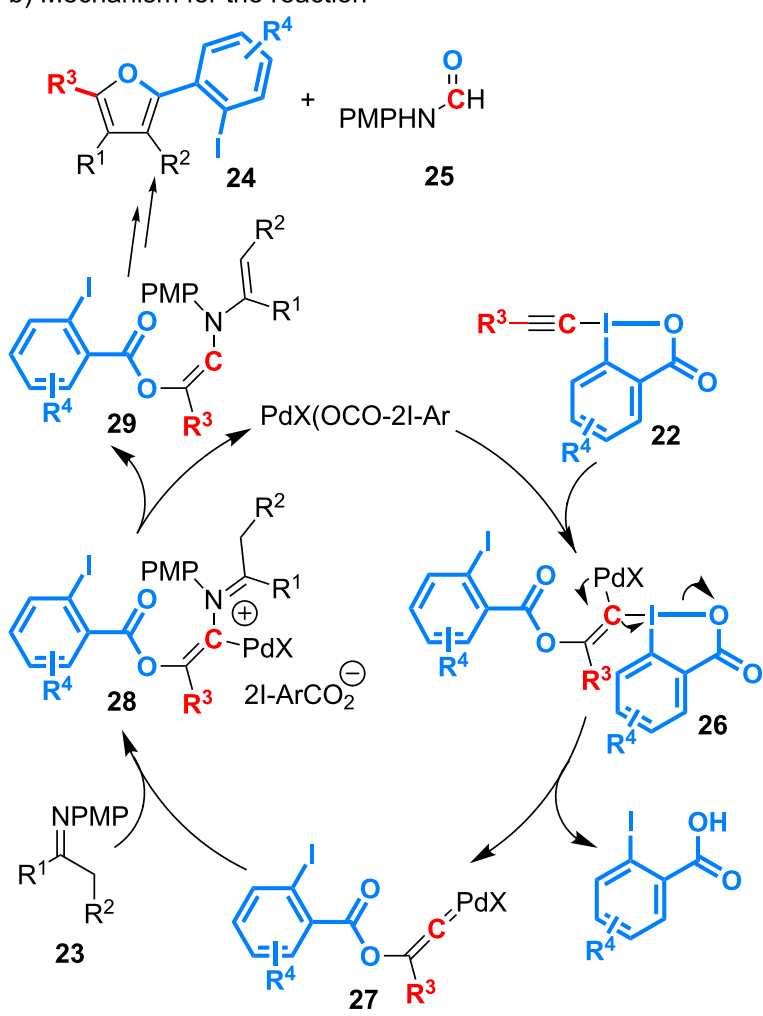

Scheme 10: Alkynylation of $\mathrm{N}$-(aryl)imines with EBX for the formation of furans.

Several isotope-labelling experiments have allowed for proposing a mechanism for this complex transformation
(Scheme 10b). The latter would first involve the addition of a $\mathrm{Pd}(\mathrm{II})$-2-iodobenzoate species to the triple bond of $\mathbf{2 2}$ to give the intermediate 26, followed by the reductive elimination of the trivalent iodine motif to afford the palladium-vinylidene $\mathbf{2 7}$. This would undergo a nucleophilic addition of the imine and a subsequent proto-demetallation to give enamine 29. A series of rearrangements including the cleavage of the triple bond and the fragmentation of the carboxylate unit, would finally lead to the furans $\mathbf{2 4}$ and the formamide $\mathbf{2 5}$.

The group of Waser has discovered an atom-economical multicomponent process between alkynylbenziodoxolones 22 and diazo compounds, which is catalyzed by the copper(I) complex $\left[\mathrm{Cu}(\mathrm{MeCN})_{4}\right] \mathrm{BF}_{4}$. The reaction gives access to versatile building blocks while generating only $\mathrm{N}_{2}$ as side-product (Scheme 11a) [46]. Worth of mention is the use of a 1,2-diimine ligand 34 that is crucial to obtain good conversions.

Compounds 31 resulting from the gem-addition of the benzoate motif and the alkynyl group are obtained from various acceptor or donor-acceptor diazo compounds $\mathbf{3 0}$, while the use of vinyldiazo derivatives $\mathbf{3 2}$ leads to enynes $\mathbf{3 3}$ arising from the vinylogous addition of the carboxylate. Significantly, the benzoyloxyalkynylation reaction can be applied to the late-stage modification of complex products such as steroids. On the other hand, both the alkyne and the iodoarene moiety can be modified through post-transformation reactions thereby increasing the molecular diversity accessible with this process. The mechanism of the reaction (Scheme 11b) would first involve the formation of the copper-carbene species $\mathbf{3 5}$, to which the carboxylate of alkynylbenziodoxolone could add to afford the intermediate 36. Final alkynyl transfer would give rise to the products $\mathbf{3 1}$ and $\mathbf{3 3}$, however, the nature of this alkynylation step remains to be elucidated.

In a subsequent study, the same group has demonstrated the ability to perform the reaction with TIPS-EBX 37 in an enantioselective manner using the cyclopropylbisoxazoline ligand $\mathbf{3 8}$ (Scheme 12) [47]. Starting from various acceptor diazo compounds, the gem-addition of the carboxylate and the alkyne proceeds with ees of up to $98 \%$ to afford $\alpha$-benzoyloxy propargylic derivatives 39. Again the strategy can be applied to the late-stage modification of steroids with high levels of diastereoselectivity.

\section{$\lambda^{3}$-lodane reagents: azidobenziodoxolone (ABX) and chlorobenziodoxolone}

In a similar manner to the previously described catalytic benzoyloxy-trifluoromethylation using Togni's reagent 5 (Scheme 4 and Scheme 5), the 1,2-benzoyloxy-azidation of alkenes can be performed in the presence of a copper catalyst with the 
a) Copper-catalyzed benzoyloxy-alkynylation of diazo compounds

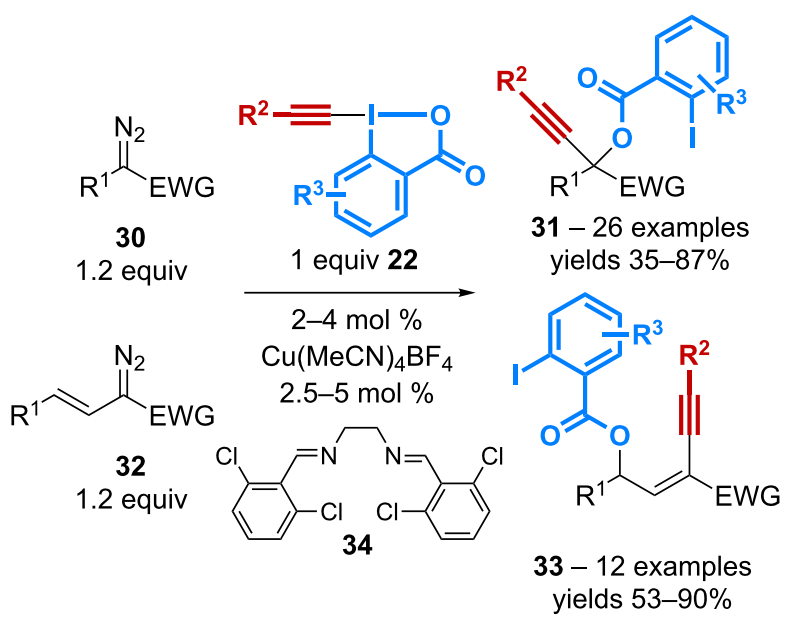

b) Mechanism of the copper-catalyzed benzoyloxy-alkynylation

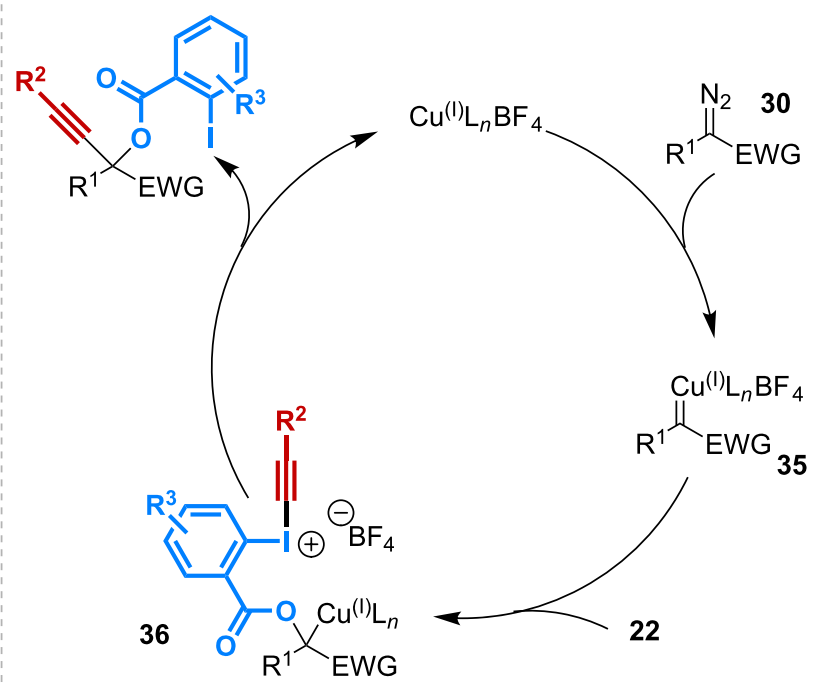

Scheme 11: Catalytic benzoyloxy-alkynylation of diazo compounds.

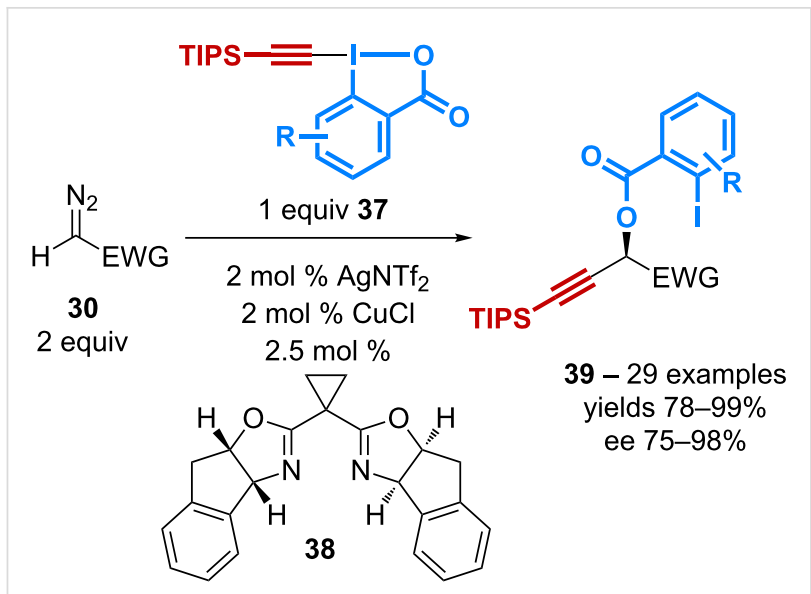

Scheme 12: Catalytic asymmetric benzoyloxy-alkynylation of diazo compounds.

azidobenziodoxolone $\mathrm{ABX}$ 40. The reaction takes place in dichloromethane using the copper(II) complex $\mathrm{Cu}(\mathrm{OTf})_{2}$ as the catalyst thereby leading to the expected products $\mathbf{4 1}$ with yields in the 26-75\% range (Scheme 13) [48]. Interestingly, an alkene diazidation reaction is observed by simply performing the transformation in $\mathrm{DMSO}$ and replacing $\mathrm{Cu}(\mathrm{OTf})_{2}$ by $\mathrm{CuI}$ as the catalyst.

Enamides 42 are also relevant substrates for the 1,2-benzoyloxy-azidation reaction. Based on a preliminary observation made during their study on catalytic trifluoromethylation of enamides [49], the group of Gillaizeau has reported the catalytic conversion of enamides with various $\mathrm{ABX}$ derivatives 44

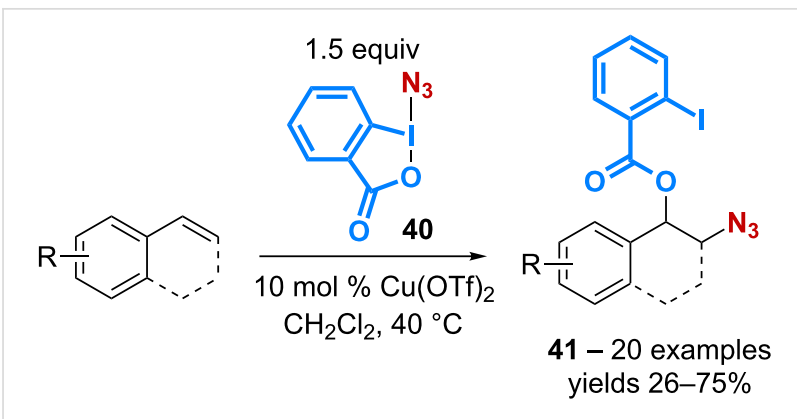

Scheme 13: Catalytic 1,2-benzoyloxy-azidation of alkenes.

[50]. A screening of various metal complexes has led the authors to demonstrate the superior ability of cheap $\mathrm{FeCl}_{2}$ to mediate the 1,2-addition thereby allowing the formation of the trans-products $\mathbf{4 3}$ with complete regio- and diastereocontrol (Scheme 14).

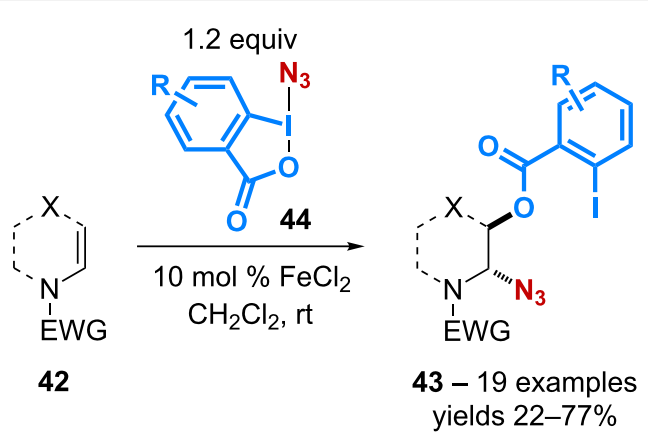

Scheme 14: Catalytic 1,2-benzoyloxy-azidation of enamides. 
The group of Hamashima has reported that various 1,2-difunctionalizations of alkenes can occur with chlorobenziodoxolone 45 [51]. Oxychlorinated, dichlorinated, azidochlorinated and chlorothiocyanated products can thus be isolated mostly from styrenyl substrates. However, the treatment of $\mathbf{4 5}$ with tetrabutylammonium iodide followed by the addition of an alkene leads to the formation of products $\mathbf{4 6}$ resulting from a 1,2benzoyloxyiodination and isolated with moderate to excellent yields (Scheme 15). The reaction is believed to take place through the formation of a hypoiodous species that activates the olefin via an iodonium intermediate.

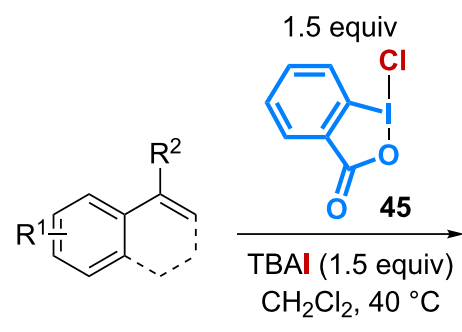

\section{Tandem catalytic couplings}

Diaryliodonium compounds, also named diaryl- $\lambda^{3}$-iodanes, are stable, easy-to-handle crystalline solids, which have found numerous applications as arylating agents since their first use in the $\alpha$-phenylation of 1,3-diones reported in the 60s [52-54]. Because of the hypernucleofuge nature of the Ar-I moiety in $\lambda^{3}$-iodanes, their reactivity is higher than that of the corresponding aryl halides, a property that has been widely exploited to develop efficient transition-metal-catalyzed cross coupling reactions [55]. The latter, however, allow for transferring only one of the two aromatic motifs of the iodonium reagents. Several elegant catalytic domino reactions, accordingly, have been recently designed to incorporate both aryl groups into the products.

\section{Cyclic diaryl- $\lambda^{3}$-iodanes}

Cyclic diaryl- $\lambda^{3}$-iodanes have been extensively studied for the preparation of complex polycyclic structures following the application of catalytic domino reactions. The group of Hayashi has reported in 2004 the first example of the transformation of a cyclic diaryl- $\lambda^{3}$-iodane, for which both Ar-I bonds are used in a palladium cross-coupling reaction [56]. It relies on a double Heck reaction performed with methyl vinyl ketone in the presence of $\mathrm{Pd}(\mathrm{OAc})_{2}$ in THF, and affords the dibenzoalkylidenefluorene $\mathbf{4 7}$ in an excellent $88 \%$ yield (Scheme 16).

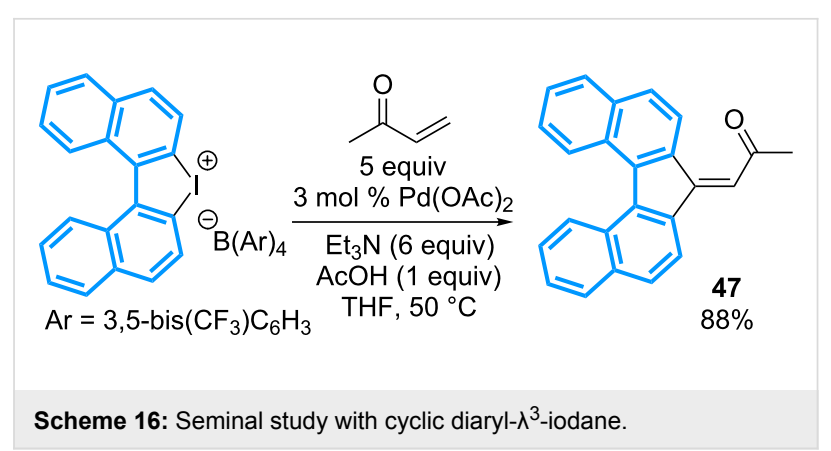

Ten years later, Huang, Wen and co-workers have demonstrated that, in the presence of both a terminal alkyne and a boronic acid, various cyclic diaryl- $\lambda^{3}$-iodanes undergo a transition-metal catalyzed cascade reaction to afford alkylidenefluorenes 49 (Scheme 17) [57]. In terms of mechanism, a $\mathrm{Pd}(0) / \mathrm{Cu}(\mathrm{I})$-catalyzed Sonogashira coupling reaction from the iodonium salt $\mathbf{4 8}$ delivers a 2-alkynyl-2'-iodoarene $\mathbf{5 0}$ that, then, cyclizes to $\mathbf{5 1}$ via insertion of the $\operatorname{Pd}(0)$ species into the iodoarene moiety and migratory addition into the proximal alkyne. Transmetalation of the vinylpalladium with the boronic acid and reductive elimination finally leads to alkylidenefluorenes 49. This multicomponent strategy allows the variation of the alkyne, the boronic acid and the diaryliodonium salts, but the use of non-symmetrical diaryl- $\lambda^{3}$-iodanes raises the issue of regioselectivity.

This strategy has been then extended to the preparation of alkyne-substituted alkylidenefluorenes $\mathbf{5 3}$ by replacing the arylboronic acid with a second equivalent of the terminal alkyne and performing the reaction at $35^{\circ} \mathrm{C}$ (Scheme 18) [58].

Importantly, the reaction with non-symmetrical diaryl- $\lambda^{3}$ iodanes gives the corresponding products with high regioselectivities, when an $o$-methyl substituent is present on one aromatic ring. The reaction can also be performed sequentially with the isolation of the iodoaryl intermediate, which can be resubmitted to the cyclization conditions in the presence of a different terminal alkyne, or an activated alkene.

The same authors have then showed that the reaction of cyclic diaryl- $\lambda^{3}$-iodanes in the presence of internal alkynes and the catalytic system $\mathrm{Pd}(\mathrm{OAc})_{2}-\mathrm{PCy}_{3}$ affords functionalized phenanthrenes 54 in moderate to good yields (Scheme 19) [59].

Indoles also are relevant substrates for the tandem arylation with cyclic diaryl- $\lambda^{3}$-iodanes, allowing the preparation of dibenzocarbazoles 55 in moderate yields (Scheme 20) [60]. The reaction is catalyzed simply by $\mathrm{Pd}(\mathrm{OAc})_{2}$ in the absence of any ligands, and tolerates a variety of substituents on both the indole and the iodonium salt. However, the atom-economy of the reac- 
a) Synthesis of alkylidenefluorenes $\mathbf{4 9}$ from cyclic diaryl- $\lambda^{3}-$ iodanes 48

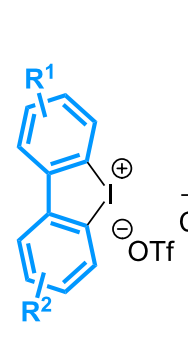

48

$\mathrm{R}^{1}$ or $\mathrm{R}^{2}=\mathrm{H}$, OMe, $t-\mathrm{Bu}, \mathrm{F}, \mathrm{CF}_{3}, \mathrm{CN}$

$\mathrm{R}^{3}=$ aryl, alkyl, ester b) Mechanism of the catalytic domino reaction

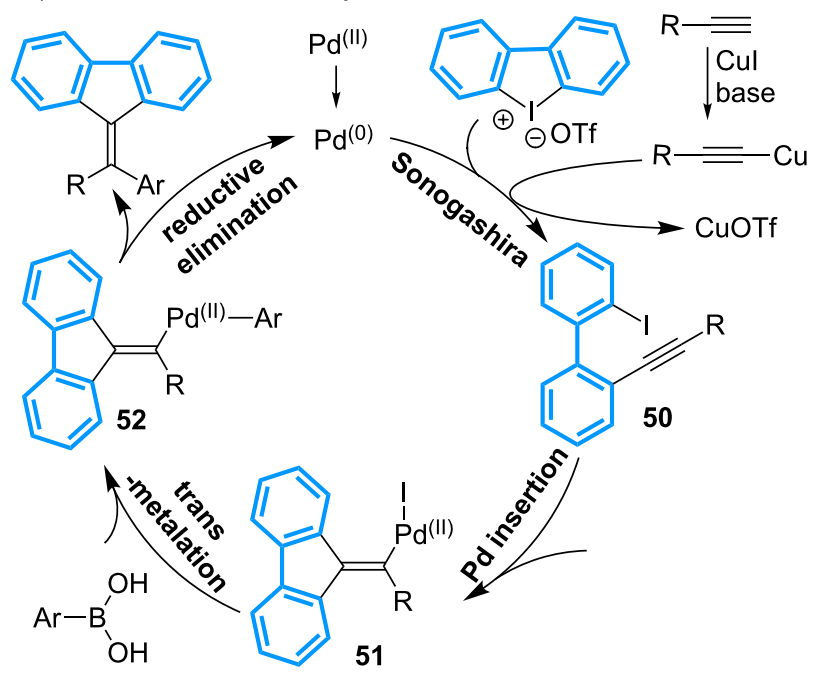

Scheme 17: Synthesis of alkylidenefluorenes from cyclic diaryl- $\lambda^{3}$-iodanes.
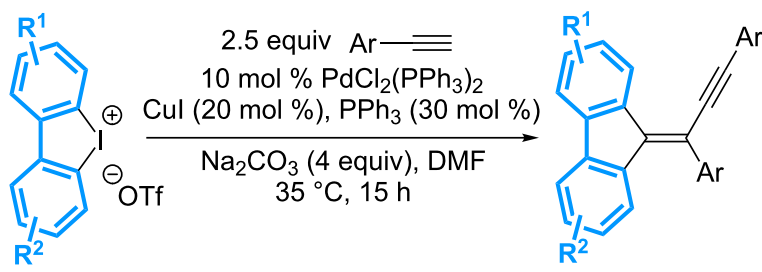

53 - 20 examples yields $54-98 \%$

Scheme 18: Synthesis of alkyne-substituted alkylidenefluorenes.
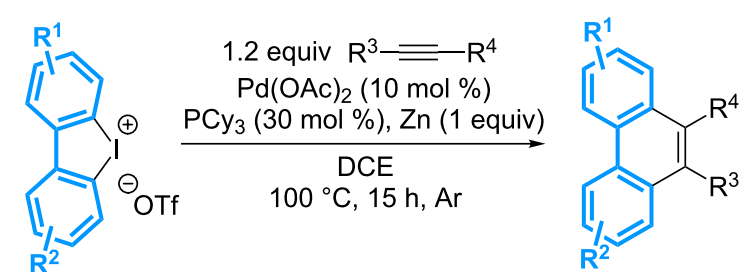

$\mathrm{R}^{1}$ or $\mathrm{R}^{2}=\mathrm{H}, \mathrm{Me}, \mathrm{OMe}, \mathrm{F}, t-\mathrm{Bu}, \mathrm{CO}_{2} \mathrm{Me}$ $\mathrm{R}^{3}$ or $\mathrm{R}^{4}=$ aryl, alkyl, ester, amide, TMS

$54-25$ examples yields $51-89 \%$

Scheme 19: Synthesis of phenanthrenes from cyclic diaryl- $\lambda^{3}$-iodanes.

tion is limited by the need to use the iodonium salts in slight excess (1.5 equivalents).

Another multicomponent reaction has been designed for the preparation of triazolophenanthridines $\mathbf{5 6}$ that are obtained in a one-pot manner by combination of a cyclic diaryl- $\lambda^{3}$-iodane with sodium azide and a terminal alkyne, in the presence of $10 \mathrm{~mol} \%$ of CuI (Scheme 21) [61]. The expected triazolophenanthridines were generally isolated in good to excellent yields,

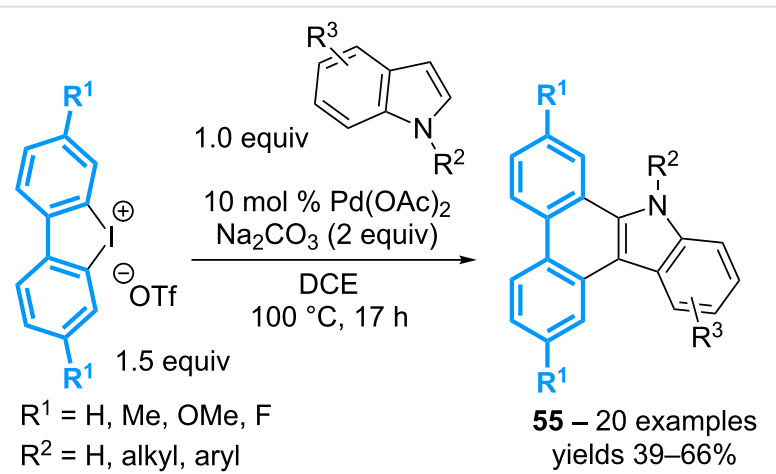

$\mathrm{R}^{3}=\mathrm{Me}, \mathrm{OMe}, \mathrm{Cl}, \mathrm{F}, \mathrm{CN}, \mathrm{CO}_{2} \mathrm{Me}$

Scheme 20: Synthesis of dibenzocarbazoles from cyclic diaryl- $\lambda^{3}-$ iodanes.

but the presence of strong electron-donating or withdrawing groups on the phenylacetylene moiety proved to be detrimental to the conversion. In addition, mixtures of regioisomeric products are generally obtained starting from non-symmetrical diaryl- $\lambda^{3}$-iodanes. A series of reactions has been performed to gain insight into the mechanism that first involves the formation of a 2'-iodobiphenyl-2-azide promoted by the copper complex. The latter then catalyzes an intermolecular $[3+2]$ cycloaddition with the alkyne. Finally, the copper-triazole moiety inserts intramolecularly into the second Ar-I bond, allowing a ring closure after reductive elimination.

Starting from the ortho- $N$-(acyl)diaryl- $\lambda^{3}$-iodanes $\mathbf{5 7}$, a combination of copper and palladium catalysis, in the presence of a phosphine ligand, induces the internal $O$-arylation of the proximal amide moiety, followed by a subsequent metal-catalyzed coupling-reaction with the resulting Ar-I motif (Scheme 22) 
<smiles>[O-][R]1ccc2c(c1)-c1cc[R]cc1-2</smiles>

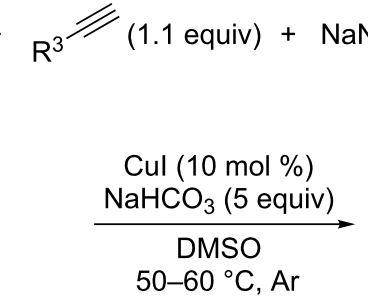

34 examples yields $33-95 \%$

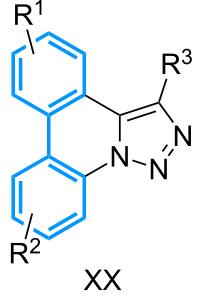

$\mathrm{XX}$
$\mathrm{R}^{1}$ or $\mathrm{R}^{2}=\mathrm{H}, \mathrm{Me}$, OMe, $\mathrm{F}, t-\mathrm{Bu}, \mathrm{CO}_{2} \mathrm{Me}$

$\mathrm{R}^{3}=$ aryl, thiophenyl, alkyl, ester, amide, TMS

Scheme 21: Synthesis of triazolophenantridines from cyclic diaryl $-\lambda^{3}-$ iodanes.

[62]. Hence aryl- and alkyl-substituted terminal alkynes can be coupled via a Sonogashira reaction when $\mathrm{PPh}_{3}$ is used as ligand, while the use of diphenylphosphinoferrocenyl ligand (dppf) allows the Heck-type coupling of acrylates, vinyl ketones and electron-poor styrene derivatives. This relayed strategy can therefore be applied to non-symmetrical cyclic diaryliodonium species, thereby affording a library of functionalized benzoxazoles 58 with complete regiocontrol.

The group of Zhang has developed a one-pot procedure for the sequential difunctionalization of cyclic diaryl- $\lambda^{3}$-iodanes (Scheme 23) [63]. The first step relies on the copper-catalyzed coupling between an anthranilic acid derivative and the biphenyl moiety. The resulting iodoarene product is then submitted to a Sonogashira coupling reaction, allowing the onepot preparation of a library of biphenyl products 59 in moderate to good yields. Nevertheless, a two-fold excess of the iodonium triflate is needed to secure a good conversion, a point that limits again the atom-economy of the overall process.

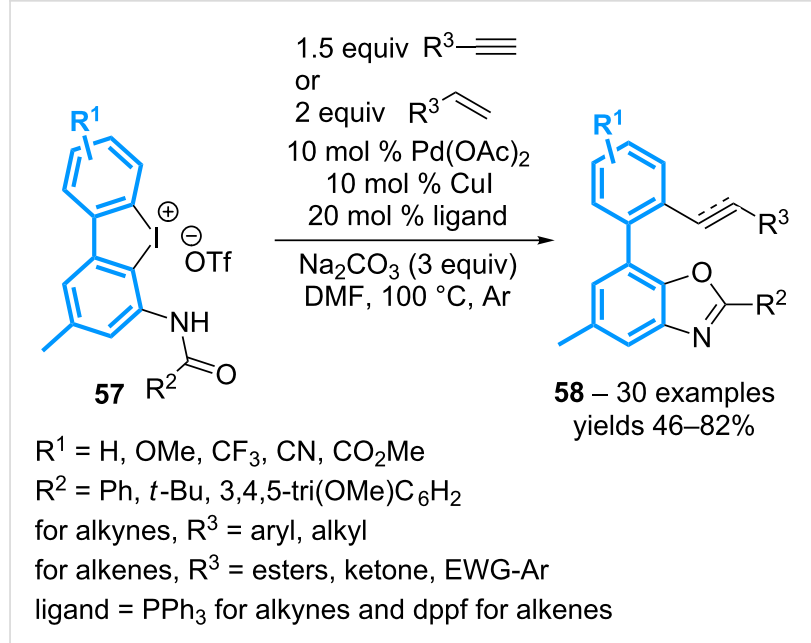

Scheme 22: Synthesis of functionalized benzoxazoles from cyclic diaryl- $\lambda^{3}$-iodanes.

Similarly, the group of Liu has described the double Suzuki-Miyaura coupling reaction of cyclic diaryl- $\lambda^{3}$-iodanes with various aryl- and heteroarylboronic acids for the formation of $o$-tetraaryls 60 (Scheme 24) [64]. The reaction generally requires only $1 \mathrm{~mol} \%$ of $\mathrm{Pd}(\mathrm{dba})_{2}$ to afford the expected products in good to high yields. It is worth mentioning that a comparative test starting from a 2,2'-diiodobiaryl has led to a much

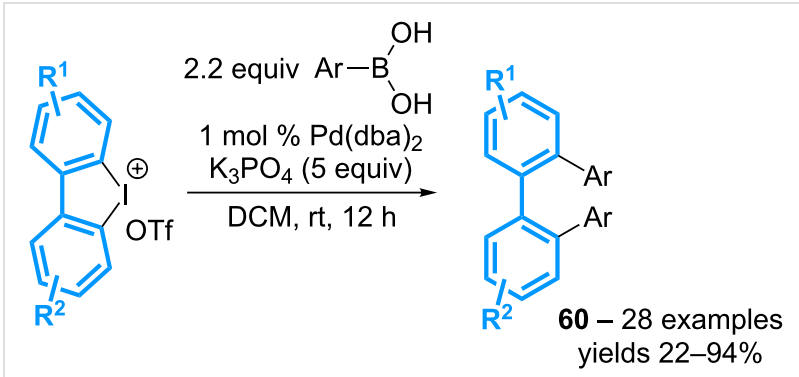

Scheme 24: Double Suzuki-Miyaura coupling reaction of cyclic diaryl$\lambda^{3}$-iodanes.

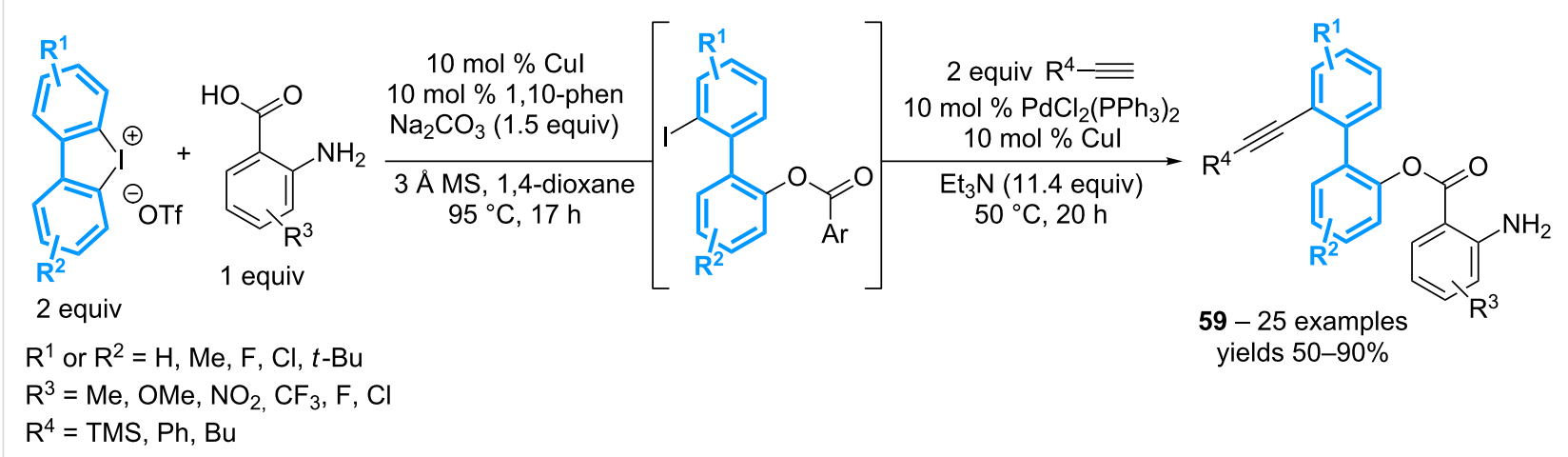

Scheme 23: Sequential difunctionalization of cyclic diaryl- $\lambda^{3}$-iodanes. 
lower yield when compared to that obtained from the corresponding diaryl- $\lambda^{3}$-iodane.

In 2011, the group of Detert has reported the first example of a palladium-catalyzed double $\mathrm{C}-\mathrm{N}$ bond formation starting from the cyclic (phenyl)(pyrido)- $\lambda^{3}$-iodane 61 (Scheme 25) [65]. The reaction requires the use of $4 \mathrm{~mol} \%$ of $\mathrm{Pd}_{2}(\mathrm{dba})_{3}, 12 \mathrm{~mol} \%$ of Xantphos, 2.8 equivalents of $\mathrm{Cs}_{2} \mathrm{CO}_{3}$ and 1.2 equivalents of benzylamine to afford the corresponding $\delta$-carboline in a $65 \%$ yield.

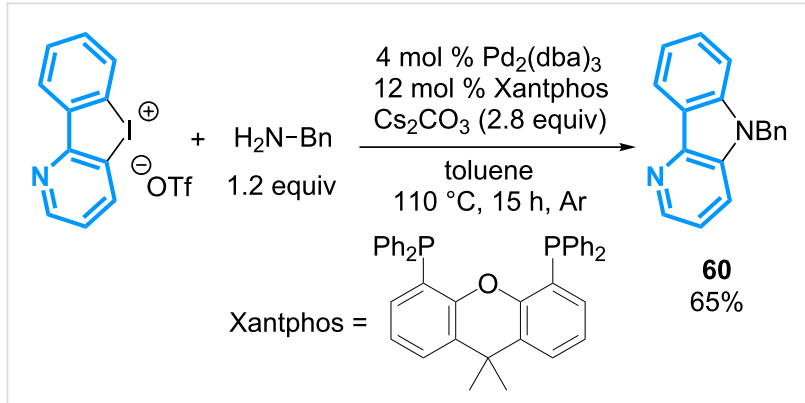

Scheme 25: Synthesis of a $\delta$-carboline from cyclic diaryl- $\lambda^{3}$-iodane.

Two years later, the group of Nachtsheim has designed a similar strategy for the preparation of $N$-(aryl)carbazoles $\mathbf{6 1}$ from cyclic diaryl- $\lambda^{3}$-iodanes (Scheme 26) [66]. The palladium phosphine ligand plays a crucial role as a bidentate ligand with a bite angle greater than $100^{\circ}$ such as DPEphos $\left(104^{\circ}\right)$ or Xantphos $\left(108^{\circ}\right)$ significantly improves the yields. The reaction applies to a series of anilines and aliphatic amines, but electron-poor anilines afford better results than their electron-rich congeners, while a hindered amine $\left(t-\mathrm{BuNH}_{2}\right)$ completely inhibits the reaction.

Shortly after, a similar synthesis of carbazoles involving $\mathrm{Cu}(\mathrm{OAc})_{2}$ as the catalyst in the presence of ethylene glycol both as a ligand and the co-solvent has been reported (Scheme 27) [67]. A variety of amines such as anilines, sulfonamides and aliphatic amines has been utilized though in large excess. But in

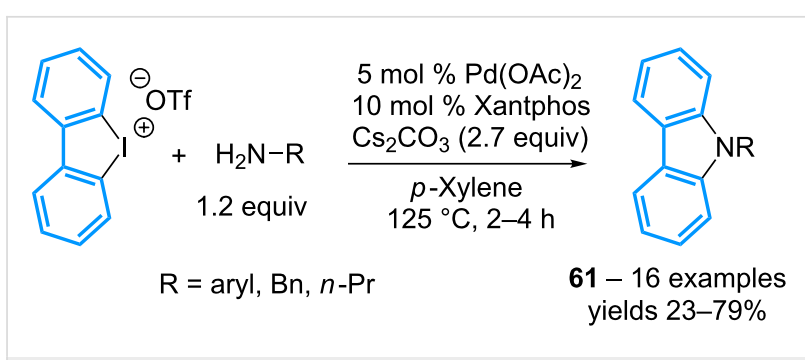

Scheme 26: Synthesis of $N$-(aryl)carbazoles from cyclic diaryl- $\lambda^{3}$ iodanes.

contrast to the previous method, electron-rich anilines proved to be better candidates for this reaction than the electron-poor analogs.

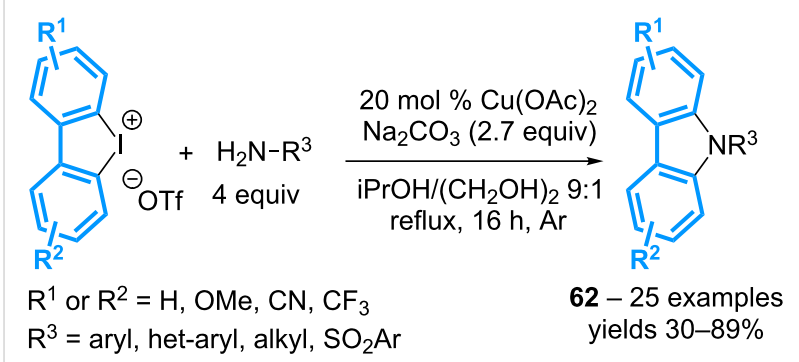

Scheme 27: Synthesis of carbazoles from cyclic diaryl- $\lambda^{3}$-iodanes.

The group of Jiang has very recently described a complementary method for the synthesis of carbazoles by combining cyclic diaryl- $\lambda^{3}$-iodanes with sodium azide in the presence of copper(I) thiophene-2-carboxylate $(\mathrm{CuTc})$ and triphenylphosphine. The reaction affords the expected of $\mathrm{N}-\mathrm{H}$ free derivatives 63 in moderate to high yields, irrespective of the nature of the substituents (Scheme 28) [68]. The scope of the reaction has been extended to 6-membered ring cyclic diaryl- $\lambda^{3}$-iodanes 64 . The acridines $\mathbf{6 5}$, hence, have been obtained with similar yields.

The group of Shimizu has reported the formation of dibenzothiophenes $\mathbf{6 6}$ following the reaction of cyclic diaryl- $\lambda^{3}$-iodanes

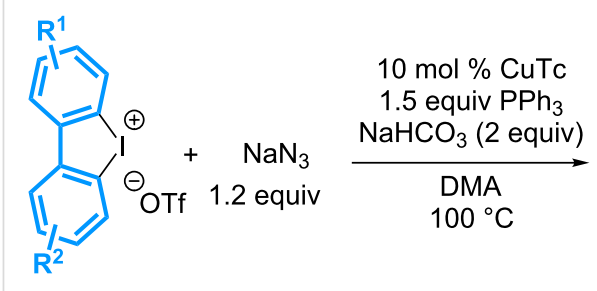

$\mathrm{R}^{1}$ or $\mathrm{R}^{2}=\mathrm{H}, \mathrm{Me}, \mathrm{Ph}, \mathrm{OMe}, \mathrm{NHAc}$, $t$-Bu, $\mathrm{F}, \mathrm{Cl}, \mathrm{Br}, \mathrm{CF}_{3}$

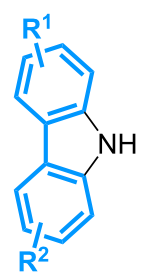

63 - 15 examples yields $42-97 \%$
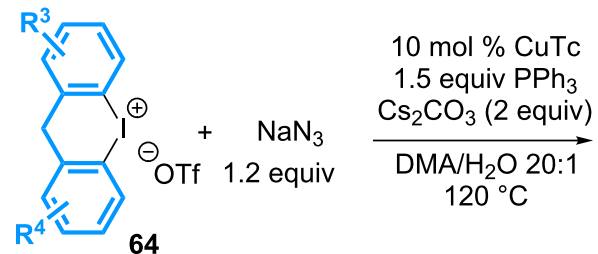

$\mathrm{R}^{3}$ or $\mathrm{R}^{4}=\mathrm{H}, \mathrm{Me}, \mathrm{OMe}, \mathrm{CO}_{2} \mathrm{Me}, \mathrm{CO}_{2} \mathrm{H}$, $t-\mathrm{Bu}, \mathrm{F}, \mathrm{Cl}, \mathrm{Br}, \mathrm{CN}, \mathrm{CF}_{3}$

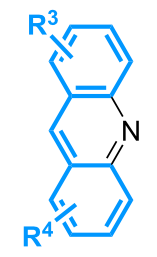

$65-21$ examples Yields 40-96\% 
with potassium thioacetate as the sulfur donor, and $\mathrm{CuCl}_{2}$ as the catalyst (Scheme 29) [69]. The reaction can be performed either in THF or DMSO, affording both symmetrical and non-symmetrical products in good to excellent yields.

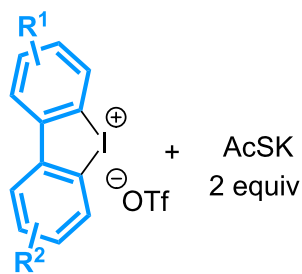

$\mathrm{R}^{1}$ or $\mathrm{R}^{2}=\mathrm{H}, \mathrm{Me}, \mathrm{OMe}$,

$\mathrm{CN}, \mathrm{Cl}, \mathrm{CF}_{3}$

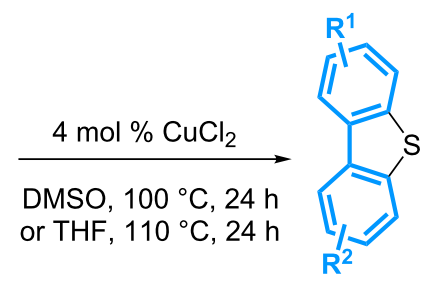

$66-9$ examples yields $70-93 \%$
Scheme 29: Synthesis of dibenzothiophenes from cyclic diaryl- $\lambda^{3}-$ iodanes.

The scope of the reaction has been extended by using a combination of $10 \mathrm{~mol} \%$ of $\mathrm{Cu}(\mathrm{OTf})_{2}, 12 \mathrm{~mol} \%$ of 1,10-phenanthroline, and 2 equivalents of potassium phosphate, as reported by the group of Jiang (Scheme 30) [70]. Six- to eight-membered sulfur heterocycles $\mathbf{6 7}$ can thus be isolated from cyclic diaryl$\lambda^{3}$-iodanes. More significantly, the reaction can be applied to acyclic diaryl- $\lambda^{3}$-iodanes (vide infra).

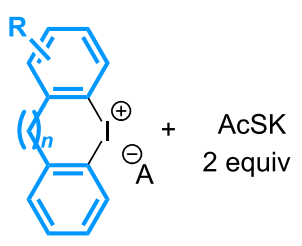

$\mathrm{R}=\mathrm{H}, \mathrm{Me}, \mathrm{OMe}, \mathrm{F}, \mathrm{Cl}, \mathrm{Br}, \mathrm{CN}, \mathrm{Ac}$ $A=$ OTs or OTf $n=0-3$

Scheme 30: Synthesis of various sulfur heterocycles from cyclic diaryl$\lambda^{3}$-iodanes.
A similar approach involving the $N$-benzyldithiocarbamate-triethylamine salt as the sulfur source and copper sulfate as the catalyst also provides dibenzothiophenes isolated generally in good to excellent yields, irrespective of the nature of the substituents (Scheme 31) [71]. The transformation has been extended to other cyclic diaryl- $\lambda^{3}$-iodanes by using $2,2^{2}$-bipyridine as the copper ligand, allowing the preparation of the corresponding thioxanthenes, phenoxathiines and dibenzothiepines in moderate to good yields.

A metal-free alternative to the previous methods of formation of sulfur heterocycles $\mathbf{7 0}$ has been reported by using elemental sulfur in the presence of cesium carbonate (Scheme 32) [72]. The strategy can be extended to the synthesis of the cyclic selenium analogs $\mathbf{7 1}$ by utilizing elemental selenium and potassium tert-butoxide. Several substituted 5- to 8-membered ring $\pi$-conjugated systems are isolated in moderate to high yields. Mechanistic investigations for the iodine/sulfur exchange have led to propose the initial formation of the trisulfur radical anion $\mathrm{S}_{3}{ }^{\cdot-} \mathbf{7 2}$, which adds to the diaryliodonium moiety thereby inducing the formation of the aryl radical 73. The latter then couples with another trisulfur radical anion to give the intermediate 74. After the base-promoted formation of the corresponding thiophenol anion 75, a cyclization delivers the expected product $\mathbf{7 0}$ by displacement of the iodine moiety.

The same group has then developed a radical method to access the corresponding sulfones from cyclic diaryl- $\lambda^{3}$-iodanes (Scheme 33) [73]. The reaction is catalyzed by a 1,10-phenanthroline-copper complex and affords the dibenzothiophene-5,5dioxides $\mathbf{7 6}$ in moderate to high yields. The transformation has been further extended to the synthesis of a new series of molecules $\mathbf{7 7}$, where the central thiophene moiety is replaced by a 6-membered heterocycle, which is substituted by a gemdimethyl or a cyclopropyl group. In this case, the reaction can be performed under metal-free conditions in the presence of a catalytic amount of dimethylethylenediamine.
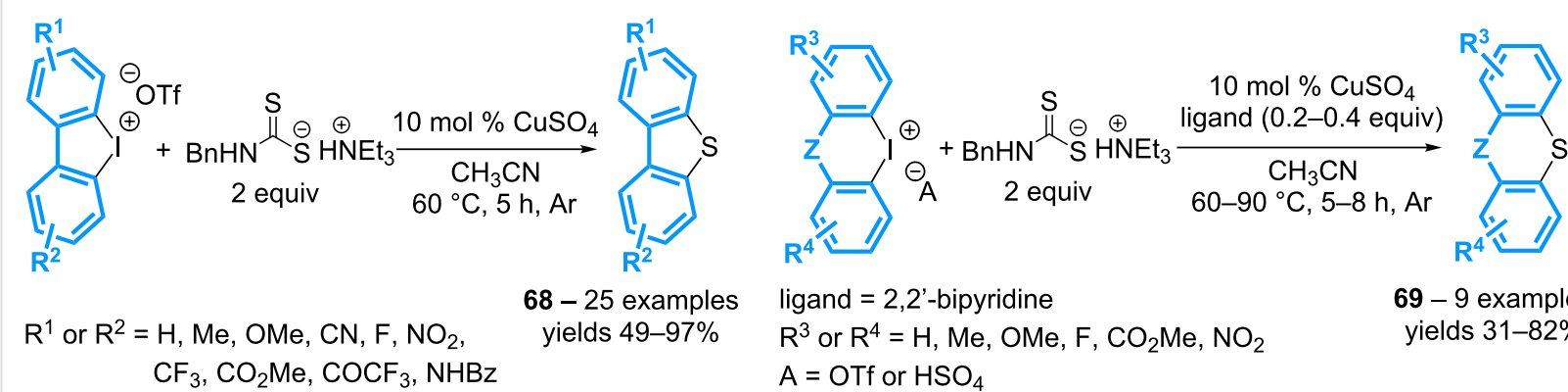

ligand $=2,2$ '-bipyridine

$\mathrm{R}^{3}$ or $\mathrm{R}^{4}=\mathrm{H}, \mathrm{Me}, \mathrm{OMe}, \mathrm{F}, \mathrm{CO}_{2} \mathrm{Me}, \mathrm{NO}_{2}$

$69-9$ examples

$\mathrm{A}=\mathrm{OTf}$ or $\mathrm{HSO}_{4}$

$\mathrm{Z}=\mathrm{CH}_{2}, \mathrm{O},\left(\mathrm{CH}_{2}\right)_{2}$ 
a) Metal-free formation of sulfur and selenium heterocycles
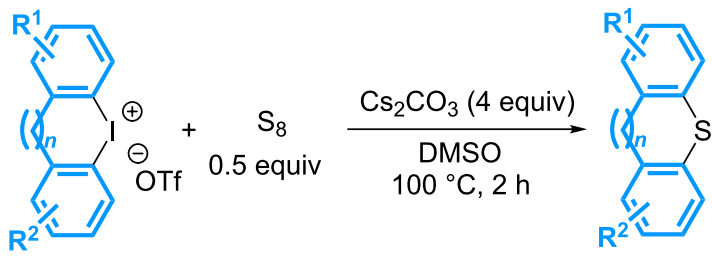

$\mathrm{R}^{1}$ or $\mathrm{R}^{2}=\mathrm{H}, \mathrm{Me}, \mathrm{OMe}, \mathrm{F}, \mathrm{Cl}, \mathrm{Br}$,

70 - 21 examples $t$-Bu, Ac, NHAc, Ar, CN, $\mathrm{CF}_{3}$

$n=0-3$
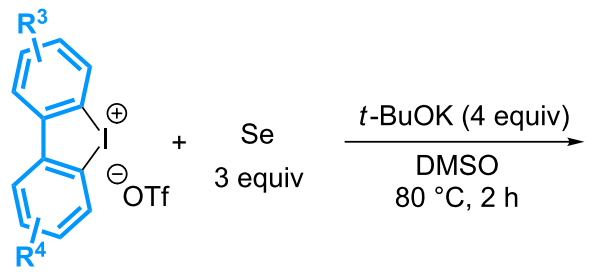

$\mathrm{R}^{3}$ or $\mathrm{R}^{4}=\mathrm{H}, \mathrm{Me}, \mathrm{OMe}, \mathrm{Cl}, \mathrm{Br}$

$t-\mathrm{Bu}, \mathrm{NHAc}, \mathrm{Ar}, \mathrm{CN}, \mathrm{CF}_{3}$ b) Mechanism of the reaction
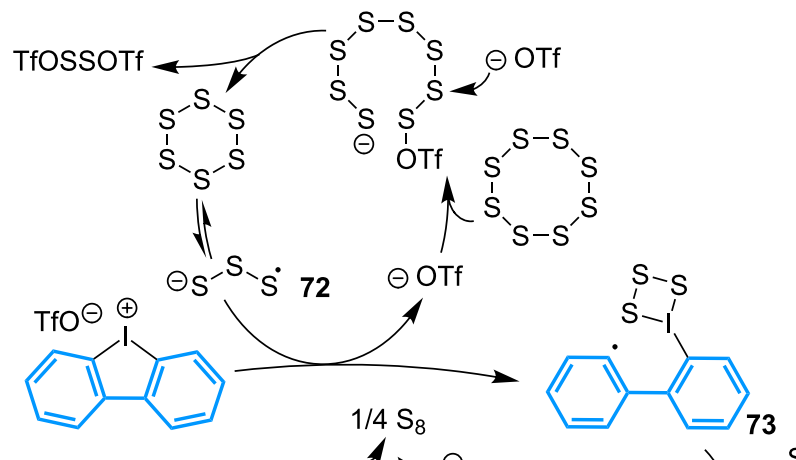

S $\Theta$

Scheme 32: Synthesis of dibenzosulfides and dibenzoselenides from cyclic diaryl- $\lambda^{3}$-iodanes

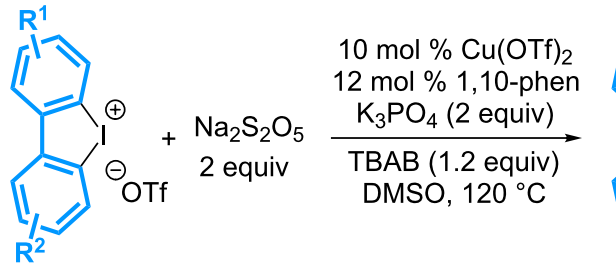

$\mathrm{R}^{1}$ or $\mathrm{R}^{2}=\mathrm{H}, \mathrm{Me}, \mathrm{OMe}, \mathrm{F}, \mathrm{Cl}, \mathrm{Br}, t-\mathrm{Bu}$, $\mathrm{Ac}, \mathrm{CO}_{2} \mathrm{Et}, \mathrm{NHAc}, \mathrm{Ar}, \mathrm{CN}, \mathrm{CF}_{3}$

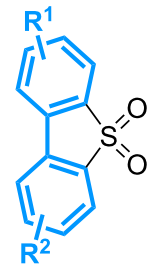

$76-25$ examples yields $42-90 \%$
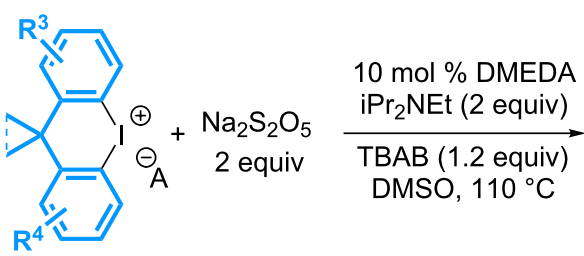

$\mathrm{R}^{3}$ or $\mathrm{R}^{4}=\mathrm{H}, \mathrm{Me}, \mathrm{F}, \mathrm{Cl}, \mathrm{Br}, t-\mathrm{Bu}$, $\mathrm{CO}_{2} \mathrm{Et}, \mathrm{Ph}, \mathrm{CF}_{3}$

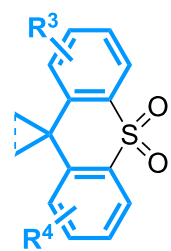

77 - 15 examples yields $40-88 \%$

Scheme 33: Synthesis of dibenzosulfones from cyclic diaryl- $\lambda^{3}$-iodanes.

\section{Linear diaryl- $\lambda^{3}$-iodanes}

When compared to cyclic diaryl- $\lambda^{3}$-iodanes, the linear analogues inherently raise a more challenging issue to address in terms of sustainability, particularly in the case of non-symmetrical reagents. As mentioned in the introduction, the first study documenting the coupling of both aromatic groups of a diaryl$\lambda^{3}$-iodane has been reported in 1995 by Bumagin and co-workers [25]. One equivalent of symmetrical diaryl- $\lambda^{3}-$ iodanes could be engaged in palladium-catalyzed cross-coupling reactions with 0.55 equivalent of sodium tetraphenylborate to afford 2 equivalents of the corresponding biphenyl products in nearly quantitative yields (Scheme 34). It is assumed that the first cross coupling reaction with the iodonium salt liberates an aryl iodide moiety, available for the second palladium-catalyzed coupling reaction.

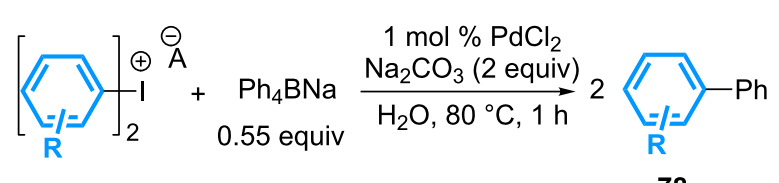

$\mathrm{R}=\mathrm{H}, 3-\mathrm{NO}_{2} \mathrm{C}_{6} \mathrm{H}_{4}, 4-\mathrm{FC}_{6} \mathrm{H}_{4}$

78

$\mathrm{A}=\mathrm{H}_{2} \mathrm{SO}_{4}, \mathrm{BF}_{4}, \mathrm{CF}_{3} \mathrm{CO}_{2}$

yields $96-98 \%$

Three years later, the high yielding $N$-arylation of $1 H-1,2,3-$ benzotriazole (BTA), utilizing symmetrical diaryl- $\lambda^{3}$-iodanes as two-fold aryl donors has been reported in the presence of $\mathrm{Pd}(\mathrm{OAc})_{2}$ and TPPTS as a water-soluble ligand, and copper(II) phenylcyclopropylcarboxylate (Scheme 35) [74]. Noteworthy, it is mentioned that $\mathrm{Ar}-\mathrm{I}$ fails to furnish the $\mathrm{N}$-arylation products 
under the same reaction conditions, leading the authors to conclude that this suggested intermediate remains in the coordination sphere of the palladium catalyst.
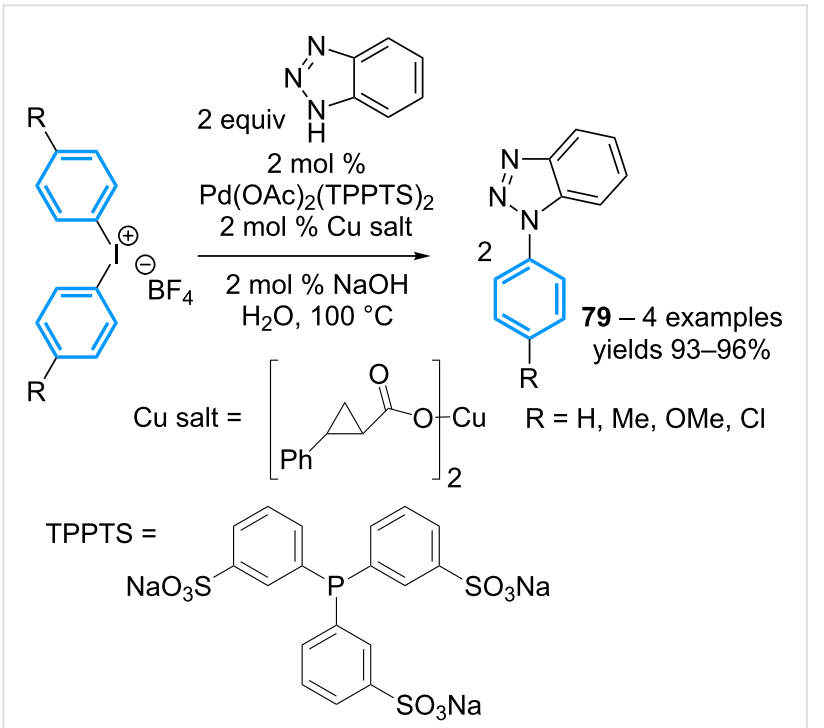

Scheme 35: $N$-Arylation of benzotriazole with symmetrical diaryl- $\lambda^{3}-$ iodanes.

In 2015, the group of Greaney has described a tandem coppercatalyzed $\mathrm{C}_{3}-\mathrm{H} / \mathrm{N}-\mathrm{H}$ arylation of indoles with diaryl- $\lambda^{3}$-iodanes (Scheme 36) [75]. The reaction first involves the use of $20 \mathrm{~mol} \%$ of $\mathrm{CuI}$ and 1.1 equivalents of di-tert-butylpyridine (dtbpy) to convert the indole to the $\mathrm{C}_{3}-\mathrm{H}$ arylated product. The released Ar-I building block, then, can be engaged in the subsequent step of $\mathrm{N}-\mathrm{H}$ arylation by adding $30 \mathrm{~mol} \%$ of dimethylethylenediamine (DMEDA) and potassium phosphate to the same pot. Symmetrical diaryl $-\lambda^{3}$-iodanes afford the diarylated indoles 80 with yields ranging from $41 \%$ to $67 \%$. More significantly, whereas non-symmetrical diaryl- $\lambda^{3}$-iodanes based on electron poor/rich aryl moieties do not provide good levels of regiocontrol in the tandem process, the use of (aryl)(dimethyluracyl)- $\lambda^{3}$-iodanes allows for obtaining difunctionalized indoles of type $\mathbf{8 1}$ resulting from the regioselective introduction of the dimethyluracyl group at the $\mathrm{N}-\mathrm{H}$ position.

The same group has then reported a remarkable domino process for the introduction of both aromatic rings of diaryl- $\lambda^{3}$-iodanes, though a small excess of this reagent is needed to obtain good yields. An initial $N$-arylation reaction of 3,5-dimethylpyrazole is performed in the presence of potassium carbonate, in xylene at $70^{\circ} \mathrm{C}$, releasing 1 equivalent of aryl iodide. The latter is then used for a sequential ruthenium-catalyzed ortho-C-H functionalization directed by the pyrazole group (Scheme 37) [76]. Starting from non-symmetrical diaryl- $\lambda^{3}$-iodanes, the electronpoorest or more sterically hindered aromatic group is first transferred to the 3,5-dimethylpyrazole. The reaction has been extended to 1,2,3-triazoles, benzotriazole, and pyrazole. In the latter case, the use of (styryl)(aryl)- $\lambda^{3}$-iodanes has also proved to be possible, with the styryl moiety being selectively transferred in the first step. The following step of $\mathrm{C}-\mathrm{H}$ activation

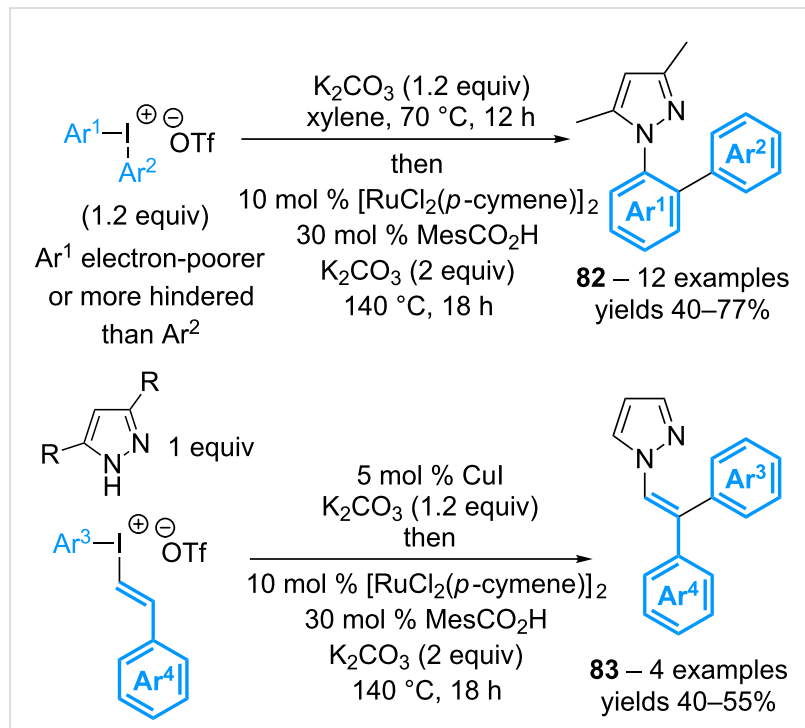

Scheme 37: Tandem $N$-arylation/C(sp $\left.{ }^{2}\right)-H$ arylation with diaryl $-\lambda^{3}-$ iodanes.

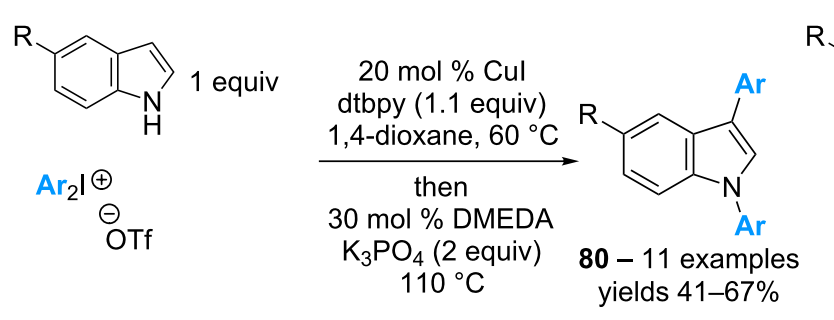

$\mathrm{Ar}=\mathrm{Ph}, 4-\mathrm{ClC}_{6} \mathrm{H}_{4}, 4-\mathrm{FC}_{6} \mathrm{H}_{4}, 4-\mathrm{MeC}_{6} \mathrm{H}_{4}, 4-\mathrm{OMeC}_{6} \mathrm{H}_{4}, 3-\mathrm{MeC}_{6} \mathrm{H}_{4}$ $\mathrm{R}=\mathrm{H}, \mathrm{Me}, \mathrm{OMe}, \mathrm{F}$
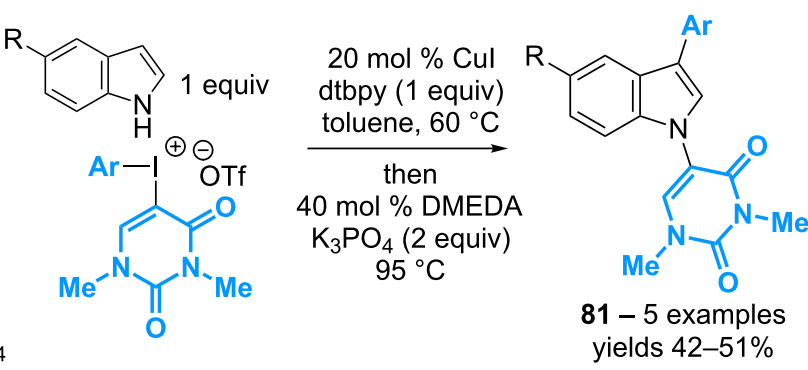
then gives access to 2,2-diarylated enamines $\mathbf{8 3}$ isolated as a single isomer with respect to the alkene geometry.

While the diarylation of anilines with cyclic diaryl- $\lambda^{3}$-iodanes for the formation of $N$-arylated carbazoles has been described in 2013 [66,67], the truly intermolecular diarylation of anilines with linear reagents has been described only in 2017 by the group Greaney [77]. Except for anilines bearing strong electronwithdrawing substituents $\left(p-\mathrm{NO}_{2}\right)$, the triarylated amines 84 can be obtained in moderate to good yields, irrespective of the substitution of the aniline and the diaryl- $\lambda^{3}$-iodane (Scheme 38 ). However, the scope of the reaction is limited to symmetrical diaryl- $\lambda^{3}$-iodanes as non-symmetrical reagents afford mixtures of $N$-arylated products in the first step of the tandem process.

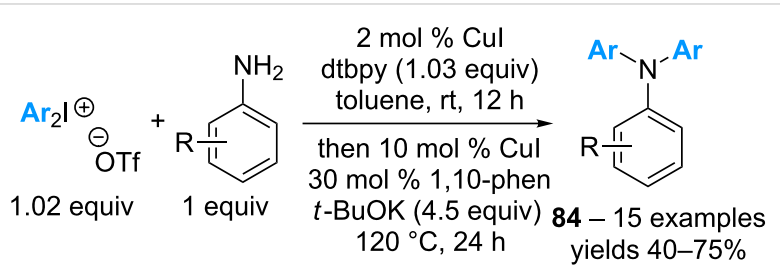

$$
\begin{aligned}
& \mathrm{Ar}=\mathrm{Ph}, 4-\mathrm{Z}-\mathrm{C}_{6} \mathrm{H}_{5} \text { (with } \mathrm{Z}=t-\mathrm{Bu}, \mathrm{F}, \mathrm{OMe}, \mathrm{Cl}, \mathrm{Me} \text { ), } \\
& \text { 3- } \mathrm{MeC}_{6} \mathrm{H}_{4} \\
& \mathrm{R}=\mathrm{H}, \mathrm{Me}, \mathrm{OMe}, \mathrm{F}, \mathrm{Cl}, \mathrm{Ph}
\end{aligned}
$$

Scheme 38: Catalytic intermolecular diarylation of anilines with diaryl$\lambda^{3}$-iodanes.

As mentioned in the Scheme 30, the group of Jiang has reported the formation of cyclic diarylsulfides from the corresponding cyclic diaryl- $\lambda^{3}$-iodanes, utilizing potassium thioacetate as the sulfur source, in the presence of $10 \mathrm{~mol} \%$ of $\mathrm{Cu}(\mathrm{OTf})_{2}$, and $12 \mathrm{~mol} \%$ of 1,10-phenanthroline [70]. This transformation has been successfully applied to linear diaryl- $\lambda^{3}$ iodanes (Scheme 39). Interestingly, symmetrical and non-symmetrical reagents bearing two electronically different aryl groups can be transferred to provide the corresponding diarylsulfide products $\mathbf{8 5}$, a result that stands in contrast to the observation made by Greaney in his study with anilines described in Scheme 38 .

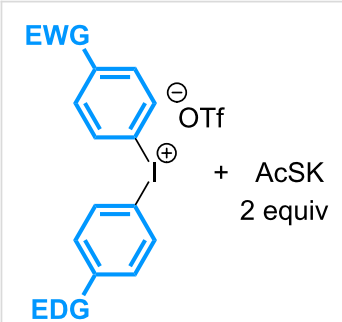

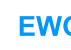

EWG

- 16 examples yields $44-87 \%$
Scheme 39: Catalytic synthesis of diarylsulfides with diaryl- $\lambda^{3}$-iodanes.

\section{Alternative to diaryl- $\lambda^{3}$-iodanes for the $\alpha$-arylation of carbonyl compounds}

In addition to their role as aryl donors in numerous metal-catalyzed couplings, diaryl- $\lambda^{3}$-iodanes are also relevant reagents to perform the $\alpha$-arylation of enolates. However, the reaction is again limited to the transfer of a single aryl group. As an alternative to address this issue of atom-economy, the group of Shafir has reported the metal- and base-free arylation of ketoesters and cyanoketones using [bis(trifluoroacetoxy)iodo]arenes $\operatorname{ArI}\left(\mathrm{OCOCF}_{3}\right)_{2}$ (Scheme 40) [78]. The reaction can also be applied to cyclic 1,3-diones with equal efficiency [79].

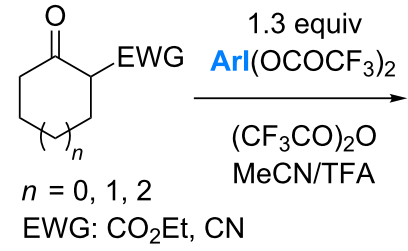<smiles>[R]C1C(=O)CCCC1=O</smiles>
$n=0,1$

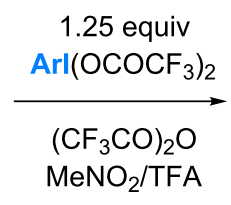

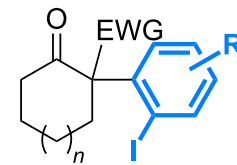

$86-18$ examples yields $37-80 \%$<smiles>[R]c1ccc(C2([R])C(=O)CCCC2=O)c(I)c1</smiles>

87 - 14 examples yields $32-75 \%$
Scheme 40: $\alpha$-Arylation of enolates using [bis(trifluoroacetoxy)iodo]arenes.

Mechanistic studies supported by DFT calculation have led to propose that the rate-determining step of the process would be the ligand exchange between TFA and the $O$-enolate (Scheme 41) [79]. The resulting cationic intermediate $\mathbf{8 8}$ could rapidly evolve through a $[3,3]$ rearrangement. Even though the $C$-enolate $\mathbf{8 9}$ is more stable than its $O$-tautomer $\mathbf{8 8}$, the rearrangement step seems to be much faster. The use of the radical scavenger TEMPO had no effect on the reaction outcome suggesting that the initial hypothesis is correct. By screening additives, it was shown that the hypervalent iodine could be quickly generated in situ by using Oxone as a terminal oxidant, thereby allowing for extending the scope of the reaction in terms of iodoarenes.

\section{Tandem oxidation-catalytic couplings}

A large range of oxidation reactions can be performed with [bis(acyloxy)iodo] arenes best represented by the commercially available reagents $\mathrm{PhI}(\mathrm{OAc})_{2}$ and $\mathrm{PhI}(\mathrm{OCO} t-\mathrm{Bu})_{2}$. These $\lambda^{3}$-iodanes have been widely used in atom-transfer reactions, particularly for the generation of metal-bound nitrenes that are highly active species for the aziridination of alkenes and the direct amination of benzylic, allylic or tertiary $\mathrm{C}\left(\mathrm{sp}^{3}\right)-\mathrm{H}$ bonds 


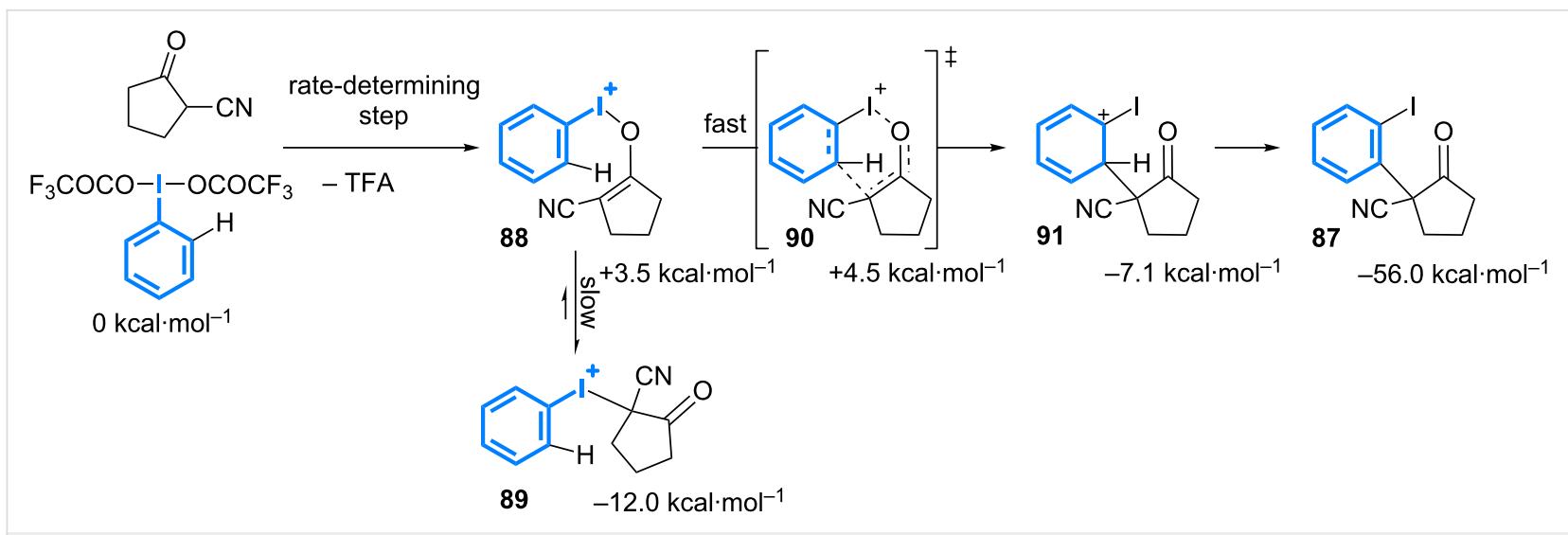

Scheme 41: Mechanism of the a-arylation using [bis(trifluoroacetoxy)iodo]arene.

[80-85]. Seminal catalytic nitrene transfers mediated by $\lambda^{3}$-iodanes [86-89] were described from iminoiodinanes of general formula $\mathrm{PhI}=\mathrm{NR}$ that can be prepared mainly from sulfonamides [90]. However, the scope of catalytic $\mathrm{C}\left(\mathrm{sp}^{3}\right)-\mathrm{H}$ amination and alkene aziridination reactions has been greatly enhanced following the discovery of practical procedures for the in situ generation of iminoiodinanes, a synthesis which is known to be troublesome [91-93]. According to these protocols and following the design of dirhodium(II) complexes, highly efficient catalytic nitrene transfers have been reported from carbamates [92], sulfamates [94-97], ureas and guanidines [98], sulfamides [99], hydroxylamine-derived sulfamates [100], carbamimidates [101], and sulfonimidamides [102-107]. These reactions involve the formation of a metal-bound nitrene that can insert into a $\mathrm{C}\left(\mathrm{sp}^{3}\right)-\mathrm{H}$ bond or a $\pi$-bond via the asynchronous concerted addition of a singlet species or a stepwise radical pathway (Scheme 42) [83,84].

While these transformations cannot be performed under conditions catalytic in iodine, recent investigations have revealed the possibility to value the iodoarene side-product in a subsequent one-pot palladium-catalyzed cross-coupling reaction. The use of a sulfonimidamide $\left(\mathrm{S}^{*} \mathrm{NH}_{2}\right)$, as a chiral nitrene precursor, in combination with the chiral dirhodium(II) complex $\mathrm{Rh}_{2}(S \text {-nta })_{4}$ has led to the discovery of intermolecular $\mathrm{C}\left(\mathrm{sp}^{3}\right)-\mathrm{H}$ amination reactions that proceed from hydrocarbons used as the limiting components, with nearly quantitative yields and complete diastereoselectivity [102-105]. Such a highly efficient atomtransfer process has provided the opportunity to design a tandem of $\mathrm{C}-\mathrm{N}$ and $\mathrm{C}-\mathrm{C}$ bond-forming reactions that relies on an initial step of catalytic nitrene addition. The latter would release the iodoarene that could be coupled to a suitable functionality previously introduced on the starting material. The strategy has been first validated from TMS-protected alkyne derivatives via a tandem of $\mathrm{C}\left(\mathrm{sp}^{3}\right)-\mathrm{H}$ amination/silaSonogashira-Hagihara coupling (Scheme 43) [108].

The overall process affords complex nitrogen-containing compounds 92 with very good yields and complete stereocontrol starting from benzylic, allylic and adamantyl substrates. In addition, the preparation of substituted [bis(acyloxy)iodo] arenes following the reaction of iodoarenes with sodium perborate<smiles>[R]C=C([R])[R]</smiles> 


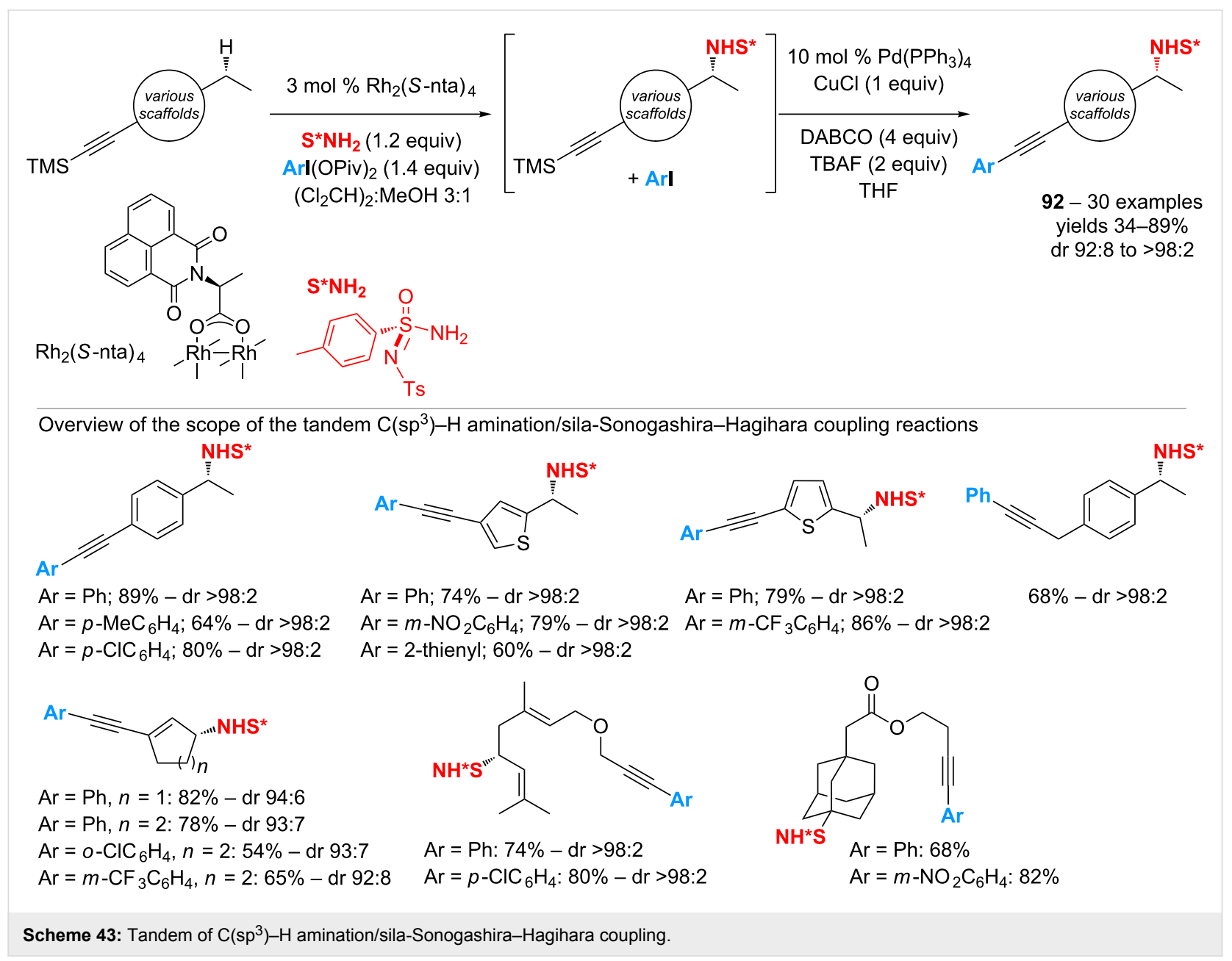

enables the introduction of various aryl groups on the alkyne moiety.

However, as a limitation of this study, the reaction allows for recycling at best 1 equivalent of the iodoarene while it involves the use of 1.4 equivalents of the $\lambda^{3}$-iodane. Moreover, it requires the design of specific alkynyl substrates that reduces its scope. With the aim to address these issues, it has been demonstrated that, in addition to its role of oxidant and coupling partner, the $\lambda^{3}$-iodane can simultaneously be used as the substrate for the $\mathrm{C}\left(\mathrm{sp}^{3}\right)-\mathrm{H}$ amination reaction (Scheme 44) [109]. The catalytic auto-amination, thus, gives access to various iodoaminated intermediates that can be subsequently engaged in palladium-catalyzed Suzuki-Miyaura, Sonogashira, or Mizoroki-Heck cross-coupling reactions. Various aryl, alkenyl, or alkynyl substituents can thus be introduced in good to very good yields.

When compared to the previous strategy, not only this process enables to increase the molecular diversity, but it also displays a higher atom-efficiency as only 1.1 equivalents of the $\lambda^{3}$-iodane are required to achieve good to excellent conversions. In addition, it should be pointed out that the tandem reactions based on the auto-amination process enables to address the issue of chemoselectivity in some cases. For example, the Suzuki-Miyaura coupling allows for introducing a pyridinyl or a furyl ring that are not compatible with the rhodium-catalyzed oxidizing amination reactions.

In a similar manner, the group of Namitharan has very recently demonstrated that a one-pot palladium-catalyzed Heck coupling allows for transferring the aryl group of (diacetoxyiodo)arenes released after a metal-free methylenation reaction (Scheme 45) [110]. The latter that is performed by reacting $\mathrm{PhI}(\mathrm{OAc})_{2}$ with $\mathrm{DMSO}$, applies to amidines 97 to afford the methylene intermediates 98 The following coupling leads to 1,2-diarylated acrylamidines 99 in good yields, but only starting from iodoarenes substituted by electron-donating groups.

\section{Conclusion}

With the aim to reduce the formation of iodo-containing sideproducts, the design of tandem reactions that enable the incor- 


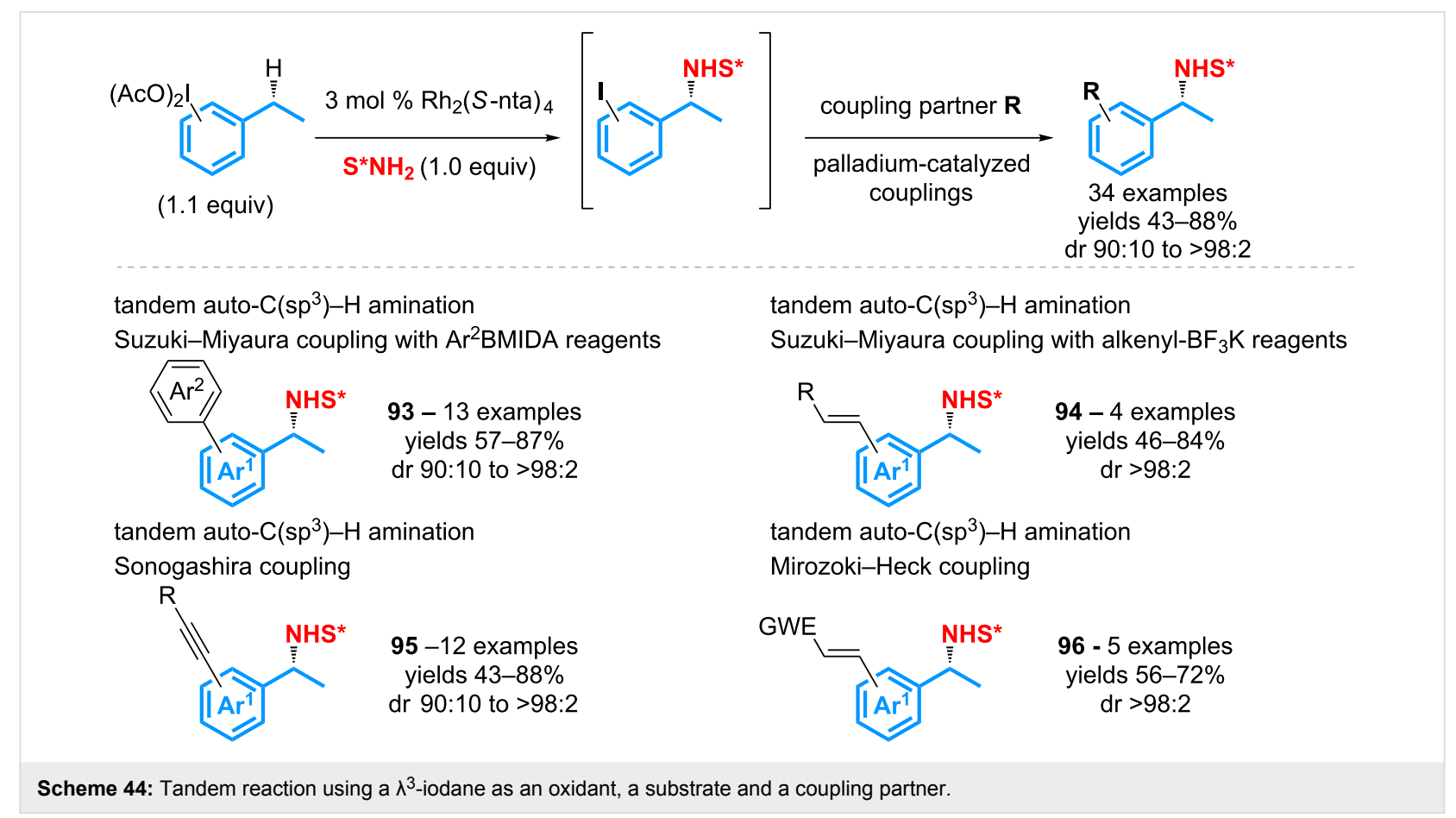

$$
\text { }
$$

Scheme 45: Synthesis of 1,2-diarylated acrylamidines with $\operatorname{Arl}(\mathrm{OAc})_{2}$.

poration of the aryl groups of $\lambda^{3}$ - or $\lambda^{5}$-iodanes into the products, has emerged as a relevant versatile alternative to the solidsupported reagents and the iodine-catalyzed transformations. Most of the achievements reported in this context have been made through the application of modern transition-metal-catalyzed methods. Simple hypervalent iodine reagents can now be considered as valuable building blocks in the synthesis of both polyfunctionalized compounds and complex polycyclic skeletons. We believe that the application of this strategy could be a source of inspiration for the conception of new multicatalytic cascades that receive increasing attention in organic synthesis $[111,112]$. Extending their scope in terms of molecular diversity and complexity is expected from their application starting from other classes of $\lambda^{3}$ - or $\lambda^{5}$-iodanes.

\section{Acknowledgements}

We wish to thank the French National Research Agency (program n ${ }^{\circ}$ ANR-11-IDEX-0003-02, CHARMMMAT ANR11-LABX-0039), the Ministère de l'Enseignement Supérieur et de la Recherche (fellowship to G. G.), and the Institut de Chimie des Substances Naturelles for their support.

\section{ORCID ${ }^{\circledR}$ iDs}

Philippe Dauban - https://orcid.org/0000-0002-1048-5529

\section{References}

1. Varvoglis, A. Hypervalent lodine in Organic Synthesis; Academic Press: London, 1997.

2. Wirth, T., Ed. Hypervalent lodine Chemistry: Modern Developments in Organic Synthesis; Topics in Current Chemistry, Vol. 224; Springer: Berlin, 2003. doi:10.1007/3-540-46114-0

3. Zhdankin, V. V. Hypervalent lodine Chemistry; John Wiley \& Sons: Chichester, 2014. doi:10.1002/9781118341155

4. Wirth, T., Ed. Hypervalent lodine Chemistry; Topics in Current Chemistry, Vol. 373; Springer: Berlin, 2016. doi:10.1007/978-3-319-33733-3

5. Stang, P. J.; Zhdankin, V. V. Chem. Rev. 1996, 96, 1123-1178. doi:10.1021/cr940424+

6. Zhdankin, V. V.; Stang, P. J. Chem. Rev. 2002, 102, 2523-2584. doi:10.1021/cr010003+

7. Zhdankin, V. V.; Stang, P. J. Chem. Rev. 2008, 108, 5299-5358. doi:10.1021/cr800332c

8. Yoshimura, A.; Zhdankin, V. V. Chem. Rev. 2016, 116, 3328-3435. doi:10.1021/acs.chemrev.5b00547

9. Ladziata, U.; Zhdankin, V. V. ARKIVOC 2006, No. ix, 26-58. doi:10.3998/ark.5550190.0007.903 
10. Zhdankin, V. V. ARKIVOC 2009, No. i, 1-62. doi:10.3998/ark.5550190.0010.101

11. Varvoglis, A. Tetrahedron 1997, 53, 1179-1255. doi:10.1016/S0040-4020(96)00970-2

12. Wirth, T. Angew. Chem. 2005, 117, 3722-3731. doi:10.1002/ange.200500115 Angew. Chem., Int. Ed. 2005, 44, 3656-3665. doi:10.1002/anie.200500115

13. Berthiol, F. Synthesis 2015, 587-603. doi:10.1055/s-0034-1379892

14. Togo, H.; Sakuratani, K. Synlett 2002, 1966-1975. doi:10.1055/s-2002-35575

15. Ochiai, M.; Miyamoto, K. Eur. J. Org. Chem. 2008, 4229-4239. doi:10.1002/ejoc.200800416

16. Richardson, R. D.; Wirth, T. Angew. Chem. 2006, 118, 4510-4512. doi:10.1002/ange.200601817 Angew. Chem., Int. Ed. 2006, 45, 4402-4404. doi:10.1002/anie.200601817

17. Ochiai, M. Chem. Rec. 2007, 7, 12-23. doi:10.1002/tcr.20104

18. Dohi, T.; Kita, Y. Chem. Commun. 2009, 2073-2085. doi:10.1039/b821747e

19. Uyanik, M.; Ishihara, K. Chem. Commun. 2009, 2086-2099. doi:10.1039/b823399c

20. Finkbeiner, P.; Nachtsheim, B. J. Synthesis 2013, 45, 979-999. doi:10.1055/s-0032-1318330

21. Singh, F. V.; Wirth, T. Chem. - Asian J. 2014, 9, 950-971. doi:10.1002/asia.201301582

22. Dohi, T.; Maruyama, A.; Yoshimura, M.; Morimoto, K.; Tohma, H.; Kita, Y. Angew. Chem. 2005, 117, 6349-6352. doi:10.1002/ange.200501688 Angew. Chem., Int. Ed. 2005, 44, 6193-6196. doi:10.1002/anie.200501688

23. Ochiai, M.; Takeuchi, Y.; Katayama, T.; Sueda, T.; Miyamoto, K J. Am. Chem. Soc. 2005, 127, 12244-12245. doi:10.1021/ja0542800

24. Thottumkara, A. P.; Bowsher, M. S.; Vinod, T. K. Org. Lett. 2005, 7, 2933-2936. doi:10.1021/ol050875o

25. Bumagin, N. A.; Luzikova, E. V.; Sukhomlinova, L. I.; Tolstaya, T. P.; Beletskaya, I. P. Russ. Chem. Bull. 1995, 44, 385-386. doi:10.1007/BF00702162

26. Zhdankin, V. V. J. Org. Chem. 2011, 76, 1185-1197. doi:10.1021/jo1024738

27. Li, Y.; Hari, D. P.; Vita, M. V.; Waser, J. Angew. Chem. 2016, 128, 4512-4531. doi:10.1002/ange.201509073

Angew. Chem., Int. Ed. 2016, 55, 4436-4454. doi:10.1002/anie.201509073

28. Pan, Z.-L.; Liu, X.-Y.; Liang, Y.-M. Tetrahedron Lett. 2004, 45, 4101-4104. doi:10.1016/j.tetlet.2004.03.158

29. Pan, Z.; Liu, X.; Liu, W.; Liang, Y. Synthesis 2005, 437-441. doi:10.1055/s-2004-834948

30. Saidhareddy, P.; Ajay, S.; Shaw, A. K. Tetrahedron 2017, 73, 4407-4417. doi:10.1016/j.tet.2017.06.001

31. Howard, J. K.; Hyland, C. J. T.; Just, J.; Smith, J. A. Org. Lett. 2013, 15, 1714-1717. doi:10.1021/ol400491p

32. Ochiai, M.; Sueda, T. Tetrahedron Lett. 2004, 45, 3557-3559. doi:10.1016/j.tetlet.2004.03.049

33. Mizuta, S.; Galicia-López, O.; Engle, K. M.; Verhoog, S.; Wheelhouse, K.; Rassias, G.; Gouverneur, V. Chem. - Eur. J. 2012, 18, 8583-8587. doi:10.1002/chem.201201707

34. Janson, P. G.; Ghoneim, I.; Ilchenko, N. O.; Szabó, K. J. Org. Lett. 2012, 14, 2882-2885. doi:10.1021/ol3011419
35. Janson, P. G.; llchenko, N. O.; Diez-Varga, A.; Szabó, K. J. Tetrahedron 2015, 71, 922-931. doi:10.1016/j.tet.2014.12.077

36. Ilchenko, N. O.; Janson, P. G.; Szabó, K. J. J. Org. Chem. 2013, 78, 11087-11091. doi:10.1021/j0401831t

37. Egami, H.; Shimizu, R.; Sodeoka, M. Tetrahedron Lett. 2012, 53, 5503-5506. doi:10.1016/j.tetlet.2012.07.134

38. Egami, H.; Shimizu, R.; Usui, Y.; Sodeoka, M. J. Fluorine Chem. 2014, 167, 172-178. doi:10.1016/j.jfluchem.2014.05.009

39. Lu, D.-F.; Zhu, C.-L.; Xu, H. Chem. Sci. 2013, 4, 2478-2482. doi:10.1039/c3sc50582k

40. Egami, H.; Kawamura, S.; Miyazaki, A.; Sodeoka, M. Angew. Chem 2013, 125, 7995-7998. doi:10.1002/ange.201303350 Angew. Chem., Int. Ed. 2013, 52, 7841-7844. doi:10.1002/anie.201303350

41. Gao, P.; Yan, X.-B.; Tao, T.; Yang, F.; He, T.; Song, X.-R.; Liu, X.-Y.; Liang, Y.-M. Chem. - Eur. J. 2013, 19, 14420-14424. doi:10.1002/chem.201303025

42. Wang, Y.; Jiang, M.; Liu, J.-T. Adv. Synth. Catal. 2014, 356, 2907-2912. doi:10.1002/adsc.201400320

43. Brand, J. P.; Waser, J. Chem. Soc. Rev. 2012, 41, 4165-4179. doi:10.1039/c2cs35034c

44. Kaschel, J.; Werz, D. B. Angew. Chem. 2015, 127, 9002-9004. doi:10.1002/ange.201503405 Angew. Chem., Int. Ed. 2015, 54, 8876-8878. doi:10.1002/anie.201503405

45. Lu, B.; Wu, J.; Yoshikai, N. J. Am. Chem. Soc. 2014, 136, 11598-11601. doi:10.1021/ja5059795

46. Hari, D. P.; Waser, J. J. Am. Chem. Soc. 2016, 138, 2190-2193. doi:10.1021/jacs.6b00278

47. Hari, D. P.; Waser, J. J. Am. Chem. Soc. 2017, 139, 8420-8423. doi:10.1021/jacs.7b04756

48. Lu, M.-Z.; Wang, C.-Q.; Loh, T.-P. Org. Lett. 2015, 17, 6110-6113. doi:10.1021/acs.orglett.5b03130

49. Rey-Rodriguez, R.; Retailleau, P.; Bonnet, P.; Gillaizeau, I. Chem. - Eur. J. 2015, 21, 3572-3575. doi:10.1002/chem.201406333

50. Bertho, S.; Rey-Rodriguez, R.; Colas, C.; Retailleau, P.; Gillaizeau, I. Chem. - Eur. J. 2017, 23, 17674-17677. doi:10.1002/chem.201704499

51. Egami, H.; Yoneda, T.; Uku, M.; Ide, T.; Kawato, Y.; Hamashima, Y. J. Org. Chem. 2016, 81, 4020-4030. doi:10.1021/acs.joc.6b00295

52. Merritt, E. A.; Olofsson, B. Angew. Chem. 2009, 121, 9214-9234. doi:10.1002/ange.200904689 Angew. Chem., Int. Ed. 2009, 48, 9052-9070. doi:10.1002/anie.200904689

53. Beringer, F. M.; Forgione, P. S.; Yudis, M. D. Tetrahedron 1960, 8 , 49-63. doi:10.1016/S0040-4020(01)93330-7

54. Beringer, F. M.; Galton, S. A.; Huang, S. J. J. Am. Chem. Soc. 1962, 84, 2819-2823. doi:10.1021/ja00873a035

55. Deprez, N. R.; Sanford, M. S. Inorg. Chem. 2007, 46, 1924-1935. doi:10.1021/ic0620337

56. Kina, A.; Miki, H.; Cho, Y.-H.; Hayashi, T. Adv. Synth. Catal. 2004, 346, 1728-1732. doi:10.1002/adsc.200404202

57. Zhu, D.; Wu, Y.; Wu, B.; Luo, B.; Ganesan, A.; Wu, F.-H.; Pi, R.; Huang, P.; Wen, S. Org. Lett. 2014, 16, 2350-2353. doi:10.1021/ol5006714

58. Liu, Z.; Luo, B.; Liu, X.; Hu, Y.; Wu, B.; Huang, P.; Wen, S. Eur. J. Org. Chem. 2016, 1110-1118. doi:10.1002/ejoc.201501544

59. Wu, Y.; Wu, F.; Zhu, D.; Luo, B.; Wang, H.; Hu, Y.; Wen, S.; Huang, P. Org. Biomol. Chem. 2015, 13, 10386-10391. doi:10.1039/C5OB01597A 
60. Wu, Y.; Peng, X.; Luo, B.; Wu, F.; Liu, B.; Song, F.; Huang, P.; Wen, S. Org. Biomol. Chem. 2014, 12, 9777-9780. doi:10.1039/C4OB02170C

61. Liu, Z.; Zhu, D.; Luo, B.; Zhang, N.; Liu, Q.; Hu, Y.; Pi, R.; Huang, P.; Wen, S. Org. Lett. 2014, 16, 5600-5603. doi:10.1021/ol502654a

62. Zhu, D.; Liu, P.; Lu, W.; Wang, H.; Luo, B.; Hu, Y.; Huang, P.; Wen, S. Chem. - Eur. J. 2015, 21, 18915-18920. doi:10.1002/chem.201503791

63. Xie, H.; Ding, M.; Liu, M.; Hu, T.; Zhang, F. Org. Lett. 2017, 19, 2600-2603. doi:10.1021/acs.orglett.7b00933

64. Zhang, Y.; Han, J.; Liu, Z.-J. J. Org. Chem. 2016, 81, 1317-1323. doi:10.1021/acs.joc.5b02255

65. Letessier, J.; Schollmeyer, D.; Detert, H. Acta Crystallogr., Sect. E 2011, 67, o2494. doi:10.1107/S1600536811034660

66. Riedmüller, S.; Nachtsheim, B. J. Beilstein J. Org. Chem. 2013, 9, 1202-1209. doi:10.3762/bjoc.9.136

67. Zhu, D.; Liu, Q.; Luo, B.; Chen, M.; Pi, R.; Huang, P.; Wen, S. Adv. Synth. Catal. 2013, 355, 2172-2178. doi:10.1002/adsc.201300271

68. Wang, M.; Fan, Q.; Jiang, X. Org. Lett. 2018, 20, 216-219. doi:10.1021/acs.orglett.7b03564

69. Shimizu, M.; Ogawa, M.; Tamagawa, T.; Shigitani, R.; Nakatani, M.; Nakano, Y. Eur. J. Org. Chem. 2016, 2785-2788. doi:10.1002/ejoc.201600357

70. Wang, M.; Wei, J.; Fan, Q.; Jiang, X. Chem. Commun. 2017, 53, 2918-2921. doi:10.1039/C6CC09201B

71. Luo, B.; Cui, Q.; Luo, H.; Hu, Y.; Huang, P.; Wen, S. Adv. Synth. Catal. 2016, 358, 2733-2738. doi:10.1002/adsc.201600405

72. Wang, M.; Fan, Q.; Jiang, X. Org. Lett. 2016, 18, 5756-5759. doi:10.1021/acs.orglett.6b03078

73. Wang, M.; Chen, S.; Jiang, X. Org. Lett. 2017, 19, 4916-4919. doi:10.1021/acs.orglett.7b02388

74. Beletskaya, I. P.; Davydov, D. V.; Moreno-Mañas, M. Tetrahedron Lett. 1998, 39, 5621-5622. doi:10.1016/S0040-4039(98)01063-6

75. Modha, S. G.; Greaney, M. F. J. Am. Chem. Soc. 2015, 137, 1416-1419. doi:10.1021/ja5124754

76. Teskey, C. J.; Sohel, S. M. A.; Bunting, D. L.; Modha, S. G.; Greaney, M. F. Angew. Chem. 2017, 129, 5347-5350. doi:10.1002/ange.201701523

Angew. Chem., Int. Ed. 2017, 56, 5263-5266. doi:10.1002/anie.201701523

77. Modha, S. G.; Popescu, M. V.; Greaney, M. F. J. Org. Chem. 2017, 82, 11933-11938. doi:10.1021/acs.joc.7b01778

78. Jia, Z.; Gálvez, E.; Sebastián, R. M.; Pleixats, R.; Álvarez-Larena, Á.; Martin, E.; Vallribera, A.; Shafir, A. Angew. Chem. 2014, 126, 11480-11483. doi:10.1002/ange.201405982 Angew. Chem., Int. Ed. 2014, 53, 11298-11301. doi:10.1002/anie.201405982

79. Wu, Y.; Arenas, I.; Broomfield, L. M.; Martin, E.; Shafir, A. Chem. - Eur. J. 2015, 21, 18779-18784. doi:10.1002/chem.201503987

80. Chang, J. W. W.; Ton, T. M. U.; Chan, P. W. H. Chem. Rec. 2011, 11, 331-357. doi:10.1002/tcr.201100018

81. Karila, D.; Dodd, R. H. Curr. Org. Chem. 2011, 15, 1507-1538. doi:10.2174/138527211795378128

82. Du Bois, J. Org. Process Res. Dev. 2011, 15, 758-762. doi:10.1021/op200046v
83. Roizen, J. L.; Harvey, M. E.; Du Bois, J. Acc. Chem. Res. 2012, 45 , 911-922. doi:10.1021/ar200318q

84. Buendia, J.; Grelier, G.; Dauban, P. Adv. Organomet. Chem. 2015, 64, 77-118. doi:10.1016/bs.adomc.2015.08.001

85. Darses, B.; Rodrigues, R.; Neuville, L.; Mazurais, M.; Dauban, P. Chem. Commun. 2017, 53, 493-508. doi:10.1039/C6CC07925C

86. Breslow, R.; Gellman, S. H. J. Am. Chem. Soc. 1983, 105, 6728-6729. doi:10.1021/ja00360a039

87. Mansuy, D.; Mahy, J.-P.; Duréault, A.; Bedi, G.; Battioni, P. J. Chem. Soc., Chem. Commun. 1984, 1161-1163. doi:10.1039/c39840001161

88. Evans, D. A.; Faul, M. M.; Bilodeau, M. T. J. Am. Chem. Soc. 1994, 116, 2742-2753. doi:10.1021/ja00086a007

89. Müller, P.; Baud, C.; Jacquier, Y. Tetrahedron 1996, 52, 1543-1548. doi:10.1016/0040-4020(95)00999-X

90. Yamada, Y.; Yamamoto, T.; Okawara, M. Chem. Lett. 1975, 361-362. doi:10.1246/cl.1975.361

91. Yu, X.-Q.; Huang, J.-S.; Zhou, X.-G.; Che, C.-M. Org. Lett. 2000, 2, 2233-2236. doi:10.1021/ol000107r

92. Espino, C. G.; Du Bois, J. Angew. Chem. 2001, 113, 618-620. doi:10.1002/1521-3757(20010202)113:3<618::AID-ANGE618>3.0.CO ;2-F

Angew. Chem., Int. Ed. 2001, 40, 598-600. doi:10.1002/1521-3773(20010202)40:3<598::AID-ANIE598>3.0.CO;29

93. Dauban, P.; Sanière, L.; Tarrade, A.; Dodd, R. H. J. Am. Chem. Soc. 2001, 123, 7707-7708. doi:10.1021/ja010968a

94. Espino, C. G.; Wehn, P. M.; Chow, J.; Du Bois, J. J. Am. Chem. Soc. 2001, 123, 6935-6936. doi:10.1021/ja011033x

95. Wehn, P. M.; Lee, J.; Du Bois, J. Org. Lett. 2003, 5, 4823-4826. doi:10.1021/ol035776u

96. Duran, F.; Leman, L.; Ghini, A.; Burton, G.; Dauban, P.; Dodd, R. H. Org. Lett. 2002, 4, 2481-2483. doi:10.1021/ol0200899

97. Estéoule, A.; Durán, F.; Retailleau, P.; Dodd, R. H.; Dauban, P. Synthesis 2007, 1251-1260. doi:10.1055/s-2007-965987

98. Kim, M.; Mulcahy, J. V.; Espino, C. G.; Du Bois, J. Org. Lett. 2006, 8, 1073-1076. doi:10.1021/ol052920y

99. Kurokawa, T.; Kim, M.; Du Bois, J. Angew. Chem. 2009, 121, 2815-2817. doi:10.1002/ange.200806192 Angew. Chem., Int. Ed. 2009, 48, 2777-2779. doi:10.1002/anie.200806192

100. Olson, D. E.; Roberts, D. A.; Du Bois, J. Org. Lett. 2012, 14 , 6174-6177. doi:10.1021/ol302895f

101. Grelier, G.; Rey-Rodriguez, R.; Darses, B.; Retailleau, P.; Dauban, P. Eur. J. Org. Chem. 2017, 1880-1883. doi:10.1002/ejoc.201700263

102.Liang, C.; Robert-Peillard, F.; Fruit, C.; Müller, P.; Dodd, R. H.; Dauban, P. Angew. Chem. 2006, 118, 4757-4760.

doi:10.1002/ange.200601248 Angew. Chem., Int. Ed. 2006, 45, 4641-4644. doi:10.1002/anie.200601248

103.Liang, C.; Collet, F.; Robert-Peillard, F.; Müller, P.; Dodd, R. H.; Dauban, P. J. Am. Chem. Soc. 2008, 130, 343-350. doi:10.1021/ja076519d

104.Lescot, C.; Darses, B.; Collet, F.; Retailleau, P.; Dauban, P. J. Org. Chem. 2012, 77, 7232-7240. doi:10.1021/jo301563j

105.Darses, B.; Jarvis, A. G.; Mafroud, A.-K.; Estenne-Bouhtou, G.; Dargazanli, G.; Dauban, P. Synthesis 2013, 2079-2087. doi:10.1055/s-0033-1339280

106. Beltrán, Á.; Lescot, C.; Díaz-Requejo, M. M.; Pérez, P. J.; Dauban, P. Tetrahedron 2013, 69, 4488-4492. doi:10.1016/j.tet.2013.02.005 
107. Mazurais, M.; Lescot, C.; Retailleau, P.; Dauban, P.

Eur. J. Org. Chem. 2014, 66-79. doi:10.1002/ejoc.201301174

108. Buendia, J.; Darses, B.; Dauban, P. Angew. Chem. 2015, 127 , 5789-5793. doi:10.1002/ange.201412364

Angew. Chem. Int. Ed. 2015, 54, 5697-5701.

doi:10.1002/anie.201412364

109.Buendia, J.; Grelier, G.; Darses, B.; Jarvis, A. G.; Taran, F.;

Dauban, P. Angew. Chem. 2016, 128, 7656-7659.

doi:10.1002/ange.201602022

Angew. Chem. Int. Ed. 2016, 55, 7530-7533.

doi:10.1002/anie.201602022

110.Pothikumar, R.; Sujatha, C.; Namitharan, K. ACS Catal. 2017, 7, 7783-7787. doi:10.1021/acscatal.7b02819

111.Xu, P.-F.; Wang, W. Catalytic Cascade Reactions; John Wiley \&

Sons: Hoboken, 2014. doi:10.1002/9781118356654

112. Tietze, L. F. Domino Reactions: Concept for Efficient Organic

Synthesis; Wiley-VCH: Weinheim, 2014. doi:10.1002/9783527671304

\section{License and Terms}

This is an Open Access article under the terms of the Creative Commons Attribution License

(http://creativecommons.org/licenses/by/4.0), which permits unrestricted use, distribution, and reproduction in any medium, provided the original work is properly cited.

The license is subject to the Beilstein Journal of Organic Chemistry terms and conditions:

(https://www.beilstein-journals.org/bjoc)

The definitive version of this article is the electronic one which can be found at:

$\underline{\text { doi:10.3762/bjoc. } 14.128}$ 